\title{
Examining the Correspondence between Self-Regulated Learning and Academic Achievement: A Case Study Analysis
}

\author{
Timothy J. Cleary, ${ }^{1,2}$ and Peter Platten ${ }^{2,3}$ \\ ${ }^{1}$ Graduate School of Applied and Professional Psychology (GSAPP), Rutgers University, 152 Frelinghuysen Road, \\ Piscataway, NJ 08854-8020, USA \\ ${ }^{2}$ Department of Educational Psychology, University of Wisconsin-Milwaukee, Milwaukee, WI 53201, USA \\ ${ }^{3}$ Deerfield Public Schools District 109, Deerfield, IL 60015, USA
}

Correspondence should be addressed to Timothy J. Cleary; timothy.cleary@rutgers.edu

Received 14 August 2012; Revised 12 October 2012; Accepted 19 October 2012

Academic Editor: Bracha Kramarski

Copyright (C) 2013 T. J. Cleary and P. Platten. This is an open access article distributed under the Creative Commons Attribution License, which permits unrestricted use, distribution, and reproduction in any medium, provided the original work is properly cited.

\begin{abstract}
Four high school students received 11 weeks of a self-regulated learning (SRL) intervention, called the Self-Regulation Empowerment Program (SREP), to improve their classroom-based biology exam scores, SRL, and motivated behaviors. This mixed model case study examined the correspondence between shifts in students' strategic, regulated behaviors with their performance on classroom-based biology tests. The authors used traditional SRL assessment tools in a pretest-posttest fashion (e.g., selfreport questionnaires, teaching rating scales) and gathered SRL data during the intervention using field note observations and contextualized structured interviews. This multidimensional assessment approach was used to establish convergence among the assessment tools and to facilitate interpretation of trends in students' biology test performance relative to their SRL processes. Key themes in this study included the following: (a) the close correspondence between changes in students SRL, biology exam performance, and SREP attendance; (b) individual variability in student performance, SRL behaviors, and beliefs in response to SREP; and (c) the importance of using a multi-dimensional assessment approach in SRL intervention research. Furthermore, this study provided additional support for the potential effectiveness of SREP in academic contexts.
\end{abstract}

\section{Introduction}

The importance and positive impact of self-regulation learning (SRL) processes on the academic achievement of students have been consistently demonstrated over the past couple of decades across a multitude of research methodologies and contexts [1-6]. Of particular relevance to educators, however, is research evaluating the impact of SRL intervention programs on the basic academic skills, such as reading, math, and writing $[2,3,5]$. This line of research is important because it underscores the potential utility of infusing SRL principles into academic intervention programs or authentic classroom instructional contexts. Another emergent applied SRL issue involves the discrepancy between the perceptions of teachers and school-based professionals regarding the importance and utility of SRL and the extent to which they directly infuse this concept into their professional activities [7-9]. In a series of recent surveys, for example, teachers and school psychologists identified SRL as a critical determinant of student success [7-9]. Interstingly, these school-based personnel also expressed poor personal knowledge in motivation and SRL processes, a lack of experience incorporating these principles into their teaching or professional activities, and a strong desire to receive professional development training regarding implementing SRL assessment tools and interventions. Such individuals may benefit from research that closely examines how SRL interventions afford opportunities for students to become more empowered and regulated learners in specific contexts and how shifts in students' regulatory and motivation processes are often linked to these intervention practices.

In recent years there has also been increased interest in studying the impact of SRL interventions with adolescent populations and in content area domains, such as science [10-14]. Sinatra and Taasoobshirazi [14] have argued that 
SRL is closely intertwined with science education because many activities within this domain, such as inquiry, conceptual change, and problem solving, often necessitate the use of metacognitive and strategic skills, two key components of self-regulated learning. On a more general level, the link between science education and SRL in the United States is bolstered when considering the recent emphasis placed on teaching students to become self-directed learners in literacy and specific content areas (e.g., science and social studies) [15] and the fact that secondary school students continue to lag internationally in science achievement [16]. Although some progress has been made in infusing SRL principles into science education or tutoring programs to enhance science achievement $[12,17,18]$, there remains a paucity of available interventions specifically designed to help high school students become more successful in navigating increasingly complex science courses.

Developing SRL interventions specifically targeting high school students is important for a variety of reasons. At the high school level, classroom-based exams often represent a key performance outcome and an integral component of students' report card grades. Thus, the skills necessary for effectively studying for exams represent a critical academic skill that needs to be taught, practiced, and refined, particularly for students who struggle academically. Although there is much information in the literature about effective test preparation skills and effective learning strategies [1921], there remains a dearth of comprehensive, applied intervention programs devoted to helping students effectively manage and overcome authentic learning challenges as they naturally arise over extended periods of time (e.g., several months). In secondary school contexts, students are often faced with many challenges or demands as they prepare for exams, most notably the need to organize and integrate large volumes of information presented within class lessons, homework assignments, and/or readings from relevant texts and resources [22]. Given that these activities often occur outside the supervision of teachers and necessitate the use of efficient regulatory strategies and processes, attention devoted to how students regulate and use such strategies as they prepare for exams is critical. The primary focus of this paper is to investigate, through four case studies, the correspondence between shifts in high school students' strategic and regulated behaviors during test preparation and their overall test performance and attendance to an SRL intervention program, called the Self-Regulation Empowerment Program.

\subsection{Definition and Conceptualization of Self-Regulated Learn-} ing (SRL). Self-regulation has been described as a multidimensional process that integrates a myriad of related yet distinct motivation beliefs and strategic and metacognitive skills [5, 23-25]. Although researchers from various theoretical backgrounds have developed innovative models of self-regulation, SREP is largely grounded in social-cognitive theory and research $[18,25,26]$. In general, social-cognitive theory emphasizes that in order to understand student learning and behavior it is critical to examine the reciprocal interactions between the social environment and various student-related processes (e.g., beliefs, attitudes). Central to this paradigm is the premise that humans have the capacity to self-regulate and to actively manage their environment, behaviors, and beliefs. Zimmerman [25] explicitly defines self-regulation as a process operationalized in terms of a contextualized, cyclical feedback loop. That is, individuals proactively plan and initiate learning attempts and then use self-generated or externally provided feedback to modify and adapt their learning methods to optimize performance.

In general, this cyclical loop has been described as a three-phase process including forethought, performance, and self-reflection. Forethought phase processes precede efforts to learn or perform and include students' goal setting, strategic planning, and motivational impetus to act. Students are more likely to engage in learning when their self-motivation beliefs are adaptive. Adaptive motivational beliefs include maintaining high self-efficacy during difficult tasks, viewing tasks as enjoyable, and believing that certain behaviors will lead to specific outcomes. Collectively, forethought processes are hypothesized to impact performance phase processes that are most prominent during learning. These latter processes include self-control (e.g., directing one's attention, structuring learning environments, and using regulatory tactics) and self-observation (e.g., tracking the quality of their learning). Self-observation is a general process that includes metacognitive monitoring (e.g., maintaining an awareness of one's thoughts and knowledge) and self-recording (e.g., writing down specific aspects of behavior or performance). These self-observational processes are critical in the cyclical loop because they generate information that students use to reflect on the quality of their skills or performance levels. In the final phase, self-reflection, individuals evaluate whether they reached their goals (i.e., self-evaluation), reflect on the causal factors of their performance (i.e., attributions), and identify specific things that need to be modified or sustained to optimize future performance (i.e., adaptive inferences; [25]).

Many theorists also argue that SRL is a teachable process that can vary across contexts and situations $[4,5,27,28]$. Research has supported this premise by showing that student motivation beliefs and regulatory actions will often differ across academic domains (e.g., science, math) and across distinct tasks within the same domains or contexts [29-31]. As will be discussed in subsequent sections, "context specificity" and "cyclical self-regulation" are two fundamental principles that guide SREP.

1.2. Core Characteristics of SREP. A few applied academic self-regulation training programs have been developed to help students engage in recursive cycles of self-regulatory thought and action [5, 19, 28, 32, 33]. Although these programs often differ in their theoretical underpinnings and instructional format, most of them are designed to enhance students' repertoire of task-specific learning strategies as well as their skills in managing and regulating their use of these strategies during learning. Collectively, these programs, including SREP, emphasize that instruction and/or tutoring support should be grounded in specific course 
material or curriculum to maximize the effectiveness of the intervention.

SREP, however, possesses several unique features. First, SREP was specifically designed to help at-risk students in middle school and high school improve their performance on authentic distal outcomes, such as preparing for monthly unit exams in science. Unlike intervention programs that are of relatively short duration or target a relatively narrow skill set or strategy, SREP seeks to enhance students' knowledge and proficiency in dynamically using a myriad of learning strategies. Additionally, SREP is designed to improve students' skill in adapting and refining their use of strategies based on course demands or obstacles that are naturally encountered during an academic semester. During this intervention, students also learn how to cope with and manage the quality of their learning and to overcome the individual-specific obstacles or challenges that may inhibit effective test preparation. By providing a highly structured environment for students to learn and practice various types of cognitive strategies (e.g., concept maps) and regulatory strategies (e.g., self-reinforcement, time management, help seeking) with feedback from a tutor or self-regulated learning coach (SRC), students can learn to independently use these skills outside the presence of tutors or teachers (e.g., studying alone at home). During sessions, students receive consistent feedback about the use of strategies and their performance on important academic outcomes, such as test scores.

SREP is also unique because it represents one of the few applied, comprehensive self-regulation intervention programs specifically designed to target test preparation in science content areas. As indicated by Schraw et al. [13], research in science education has focused on metacognition (i.e., thinking about thinking), but much less is known about how the broader concept of self-regulation can be applied to such contexts [13]. Rather than simply improving self-regulation and metacognition, SREP operates on a strong empirical and theoretical foundation from which changes in students' behavior can be understood and explained [24, 25]. By applying the three-phase model of SRL highlighted previously, SREP affords students the opportunity to engage in recursive cycles of thinking and action while independently learning science course material and preparing for unit exams. That is, students learn to engage in a feedback loop that directly parallels or mirrors the forethought, performance, and selfreflection phases as described by Zimmerman ([25]; see Section 2).

1.3. Purposes of Study. We used individual case studies to investigate the relationship between SREP instruction, observed shifts in students' strategic and regulated thoughts and behaviors, and changes in their biology test grades. Unlike most SRL intervention research studies, which are more time-limited in nature and typically evaluate change in terms of pretest-posttest analysis $[3,34]$, this study combines a pretest-posttest framework with qualitative descriptions of shifts in students' regulatory processes during the course of the intervention. These shifts included how deeply students engaged in SREP discussions, how often they attended
SREP sessions, and how frequently they reported using key strategies taught during SREP sessions. This methodological approach provides a context to examine trends between shifts in students' behaviors and changes in their biology exam scores. Researchers have recognized the need to illustrate how SRL might unfold during an intervention as well as how shifts in SRL processes and behaviors of academic strugglers, whether learning disabled or those who simply perform below expectations, are linked to more adaptive academic outcomes $[4,18]$. To capture the complex and multifaceted nature of SRL, researchers have also advocated for using a multidimensional SRL assessment approach [35]. Methodologically, a multidimensional approach facilitates convergence of multiple data sources which then can be used to strengthen interpretive statements about changes in students' SRL behaviors during an intervention.

To date, only one study has examined the relationship between SREP instruction and science performance using a multidimensional SRL assessment approach [18]. The authors implemented SREP with a small group of academically at-risk urban high school students who exhibited below average performance on biology tests during the first semester of a school year. In general, the authors reported a clinically significant increase in biology test grades, as illustrated by improvements in all students' test scores from below average to the average or above average range. Additionally, reliability change index (RCI) procedures were used to detect statistically significant changes in students' motivation beliefs and regulatory behaviors as measured with both self-report questionnaires and teacher rating scales. Furthermore, the authors included some methodological controls to strengthen claims regarding the relation between SREP instruction and the observed changes. However, to strengthen the premise that an intervention relates to observed achievement and behavioral changes in case study research, replication of findings is essential $[36,37]$. With this latter point in mind, a secondary objective of the current study was to replicate the finding that students who receive SREP show improvement in classroom-based biology test scores relative to class norms.

\section{Method}

2.1. Participants. All participants were ninth grade students enrolled in an urban high school located in a large public school district in the Midwestern region of the US. The authors used a multiple criteria screening process to select students: (a) enrollment in a ninth grade Honors biology course, (b) teacher ratings of poor student engagement and regulatory behaviors, and (c) teacher concerns about test performance [18]. Students who are enrolled in Honors classes in this high school typically exhibit stronger academic skills than their same-district peers and receive nominations from their middle school teachers. However, their overall skill levels when compared to state or national norms are average. For this study, we were primarily interested in including students with average achievement (as determined by state or national level) but who were struggling to perform 
TABLE 1: Demographic information and prior achievement data for SREP participants.

\begin{tabular}{|c|c|c|c|c|c|c|}
\hline Participant name ${ }^{a}$ & Gender & SES $^{\mathrm{b}}$ & Ethnicity & WKCE science & WKCE reading & WISC-IV screener $^{c}$ \\
\hline Vince & M & FRL & Hispanic & Proficient & Proficient & 9.0 \\
\hline Pauline & $\mathrm{F}$ & NS & Asian & Proficient & Basic & 9.7 \\
\hline Eric & M & NS & White & Advanced & Advanced & 11.7 \\
\hline John & M & FRL & Black & Proficient & Proficient & NA \\
\hline
\end{tabular}

WKCE: Wisconsin Knowledge and Concepts Examination. There are four performance categories on the WKCE, ranging from lowest to highest: minimal, basic, proficient, and advanced. WISC-IV: Wechsler Intelligence Scale for Children-Fourth Edition. NA: not available. All information was obtained from student records provided by the participating high school.

${ }^{a}$ All names are fictional. ${ }^{b}$ Lunch status was used as an indicator of SES. FRL: free-or-reduced lunch. NS: no financial support.

${ }^{\mathrm{c}}$ Average scores across three subtests $(M=10 ; \mathrm{SD}=3)$.

well in a high school science course. Hence, ninth grade students enrolled in an Honors biology class in the target high school were recruited for this study. Fourteen students were nominated by a team of teachers (biology, mathematics, English, social studies) to receive SREP. Nine of the 14 students returned parental consent forms, with five agreeing to participate in a Fall SREP training and four students agreeing to begin in a Spring session. Data is only presented for the four Spring participants (see Table 1), as the Fall semester served as a pilot program to refine the implementation procedures. None of the participants had been previously identified as having a learning disability.

2.1.1. Vince. Vince, a fourteen-year-old, Latino male, performed in the proficient range on the science and reading sections of a state standardized exam and exhibited average intellectual skills (see Table 1). He displayed an adaptive profile of cognitive and academic skills. A review of his educational records, however, showed that Vince exhibited interest and motivation to learn, but his grades were highly inconsistent in middle school. His eighth grade science teacher noted that Vince's course grades reflected low test scores. His ninth grade biology teacher expressed similar concerns, particularly with regard to the consistency of his test grades. In terms of demographics, Vince came from a lower SES background and he self-reported receiving English Language Learner (ELL) services from the first through the sixth grade (SREP session observation, April 21, 2008). Vince also reported several personal interests typical of adolescence, including playing sports and participating in Tae Kwon Do.

2.1.2. Pauline. Pauline, a fourteen-year-old, Asian female, performed in the proficient range in science and the basic range (i.e., category below proficient) in reading on a state standardized exam and displayed average intellectual skills (see Table 1). Based on high school and middle school teacher reports, Pauline typically displayed adequate motivation and effort in school. However, a review of her middle school report cards showed that Pauline struggled to attain proficiency in writing as well as on tasks requiring independent research and inquiry. These types of tasks are often linked with science classrooms. Her ninth grade teachers supported this latter finding, suggesting that her struggles with independent learning was a prime reason for referring Pauline to participate in SREP. Pauline did not qualify for free-orreduced lunch. In terms of leisure interests, she reported playing tennis for her high school.

2.1.3. Eric. Eric, a fourteen-year-old, Caucasian male, displayed advanced academic skills in science and reading as well as strong intellectual skills (see Table 1). Based on his middle school records, Eric typically displayed adequate effort in school and earned mostly B grades in his academic subjects. However, a couple of his teachers indicated that Eric did not always work up to this potential in middle school and thus displayed inconsistent motivation. His ninth grade teachers supported this claim, highlighting that his inconsistent effort and poor organization were the primary reasons for nominating him to receive SREP. Eric was not eligible for free-or-reduced lunch and his leisure interests were not available.

2.1.4. John. John, a fourteen-year-old, African American male, performed in the proficient range in both science and reading. Although John did not complete the cognitive ability screener (based on parental request), his teachers in both middle school and high school reported that he possessed strong potential to perform well in school. However, several of John's middle school teachers indicated that he often exhibited issues with regulation and self-management, including poor self-control and attention focusing skills. Collectively, his ninth grade teachers highlighted these weaknesses along with poor motivation as the primary reasons for referral to SREP. Based on school records, John received free-orreduced lunch in ninth grade.

\subsection{Measures}

2.2.1. Biology Test Scores. The authors used teacher-developed class tests covering specific units in biology as the primary measure of academic achievement. A total of eight unit exams were administered throughout the school year. The first five science exams occurred prior to SREP training and thus were considered pretest or baseline scores. However, we did not include the first exam of the school year in the pretest average score due to teacher reports that this exam differed substantially in format, structure, and content from all other exams. The remaining four pretest and three intervention exams adhered to a similar format (i.e., multiple 
choice, short answer, diagrams, and essay questions) and ranged from $0 \%$ to $100 \%$.

2.2.2. Self-Report and Rating Scales. A variety of self-report questionnaires were administered to examine student perceptions regarding their use of regulatory strategies and their self-efficacy perceptions. Multiple SRL strategy questionnaires were used to examine shifts in students' perceptions of strategy use because SREP instruction entailed frequent modeling and teaching of such strategies. Although there are several types of motivation beliefs that we could have examined, such as goal orientation and task values, we elected to comprehensively focus on self-efficacy (i.e., two separate measures) due to its central role in social-cognitive theoretical models of motivation and SRL. Moreover, prior research has established self-efficacy as one of the strongest predictors of motivated and strategic behaviors [25].

2.2.3. Self-Regulation Strategy Inventory-Self-Report (SRSI$S R$ ). The SRSI-SR is a 28 -item self-report scale designed to assess students' use of various self-regulation strategies during studying and homework completion [38]. Factor analysis indicated that the SRSI has a three-factor structure: Environment and Behavior Management $(\alpha=0.88)$, Seeking and Learning Information $(\alpha=0.84)$, and Maladaptive Behaviors $(\alpha=0.72)$. The Environment and Behavior Management scale is a 12-item subscale assessing the frequency with which students report using strategies to manage their study environment (e.g., "I try to study in a quiet place") and examines whether they engage in self-control during studying (e.g., "I tell myself to keep trying hard when I get confused"). The eight-item Seeking and Learning Information subscale measures the frequency with which students report seeking help or using specific study tactics during studying. The Maladaptive Regulatory Behavior scale includes eight items and measures the extent to which students engage in maladaptive regulatory behaviors, such as forgetfulness and avoidance (e.g., "I give up or quit when I do not understand something"). All items were worded in relation to biology class and used a five-point Likert scale ranging from 1 (almost never) to 5 (almost always) with specific anchors for each scale unit. These scales have been shown to differentiate high and low achievers in urban [38] and suburban contexts [39].

2.2.4. Self-Regulation Strategy Inventory-Teacher Rating Scale (SRSI-TRS). The SRSI-TRS is a 13-item teacher rating scale designed to assess teachers' perceptions of students' regulatory behaviors and engagement in specific classroom contexts [40]. This scale was developed as a parallel measure to the SRSI-SR. All items were worded in relation to biology class and used a five-point Likert scale ranging from 1 (almost never) to 5 (almost always). Example items include "The student asks questions in class when he or she does not understand something" and "The student monitors how well he or she learns class material." The scale has demonstrated adequate internal consistency $(\alpha=0.96)$ and predictive validity with high school students in urban contexts [40].
2.2.5. Self-Efficacy for Self-Regulated (SRL) Learning. A 10item self-efficacy for self-regulated learning measure was employed to examine students' confidence in regulating learning, such as planning and organizing schoolwork, motivating themselves to study, and structuring their study environments $[18,41]$. The self-efficacy stem phrase, "How confident are you that you can...," was followed by 10 efficacy phrases, including "Get yourself to study when there are other interesting things to do" and "Arrange a place to study without distractions." Students responded to all items using an 11-point Likert scale ranging from 0 (not confident at all) to 10 (completely confident). In addition, one item was reworded to ensure compatibility with the nature of the target school (e.g., item pertaining to library use). Different versions of this scale have been shown to exhibit adequate internal consistency, with $\alpha$ levels ranging from 0.82 to $0.85[18,42]$.

2.2.6. Self-Efficacy for Outcomes. A six-item self-efficacy scale adapted from the Patterns of Adaptive Learning Scale (PALS) was used to assess students' confidence for learning and performing in biology class [31]. The authors worded all items to reflect performance in biology class and included an 11-point Likert scale ranging from 0 (not confident at all) to 10 (completely confident) to be consistent with the other self-efficacy measure. The self-efficacy stem phrase, "How confident are you that you can...," was followed by the six items. An example item included "Understand the most difficult topics in biology if you try hard." The internal consistency of different versions of this scale has been shown to range from 0.70 to 0.88 in middle school and secondary school populations $[18,31]$.

2.2.7. Qualitative Measures. Qualitative information about students' strategy use and self-reflection processes as well as students', teachers', and parents' perceptions of social validity of SREP (i.e., acceptability, importance) were also gathered. The inclusion of social validity measures in SRL intervention research is a relatively rare phenomenon. However, it is an important type of measure that can provide supplementary information regarding the implementation and potential effectiveness of an intervention. That is, social validity measures generate information about whether direct consumers (i.e., students) and indirect consumers (i.e., teachers and parents) perceive the intervention procedures, outcomes, and goals to be valuable and/or acceptable. These types of perceptions are critical because they often determine whether interventions will be rejected or embraced during future iterations of an intervention program $[43,44]$.

2.2.8. Field Notes. As part of each session, the second author, who was an advanced doctoral student trained extensively in multidimensional assessment techniques, used a behavioral checklist to document students' verbalizations and behaviors pertaining to various aspects of SRL. This checklist was aligned with Zimmerman's [25] model of self-regulation to focus on key processes underlying each of the three phases of self-regulated learning. For example, the checklist listed self-motivational beliefs as one category for behavioral 
documentation, such as statements indicative of self-efficacy ("I can do this") or outcome expectations ("This will help me do better"). Verbal reports of using cognitive or self-regulated learning strategies at home were recorded as performance control behaviors, such as using concept maps, self-quizzing, studying in a quiet place or rewarding oneself with a snack after studying. Self-reflection processes, such as affective reactions ("I am happy that I did better on the exam") were also recorded. For each of these general categories, specific definitions derived from theoretical definitions along with example behaviors were included to facilitate accurate recording. Ample writing space for additional recording of specific behaviors and verbalizations was also provided. The second author was provided with the opportunity to ask questions and to confirm the meaning of the student behaviors and verbalizations on a weekly basis with the primary author.

2.2.9. SRL Microanalysis. SRL microanalysis is a structured interview protocol that uses highly contextualized questions targeting specific regulatory processes as students engage in particular tasks or activities $[45,46]$. In this study, questions targeting two self-reflection phase processes, attributions ("What is the main reason(s) for my exam performance?"), and adaptive inferences ("What do I need to do to improve my next test performance?") were administered following the first and second intervention biology exams. These questions provided qualitative information about how students perceived and reacted to test performance. Prior research has shown these two questions typically elicit maladaptive or nonstrategic responses in low achieving students [46, 47]. Thus, in this study, student responses to these questions were used by the self-regulated learning coach (SRC) to formally engage students in reflective discussions about the quality of their strategic thinking and approaches for subsequent biology exams (i.e., during the self-reflection module).

2.2.10. Social Validity. A nine-item social validity questionnaire was administered to students, parents, and the biology teacher (see the appendix for individual items; [18]). The measure was designed to target two aspects of social validity as defined by Wolf [44]: (a) social acceptability of procedures, and (b) social importance of effects. This scale utilized a 5-point Likert scale ranging from 1 (strongly disagree) to 5 (strongly agree), with higher scores representing greater acceptability and consumer satisfaction.

2.3. Research Design. This mixed model case study design emphasized the use of a comprehensive array of quantitative and qualitative measures to examine shifts in students' regulatory and motivation process during and following the intervention. The authors administered self-report questionnaires and a teacher rating scale at pretest and posttest, the social validity survey at posttest only, and the qualitative assessment tools during SREP sessions. The use of this multidimensionalassessment approach allowed us to examine whether students' perceptions of their regulatory behaviors and beliefs converged with teacher and SRC observations and ratings.
We also incorporated methodological controls to reduce the likelihood that extraneous variables impacted the observed changes in students' biology test scores. In terms of achievement, we used four biology exams administered over a four-month period as the index of pretest achievement. Given that participant test scores were relatively stable over a long period of time, it is highly unlikely that changes in test performance observed during the intervention were due to maturational changes. Second, we reduced the likelihood that teacher behaviors or instruction, difficulty level of biology unit, or exam difficulty served as confounding variables by using classroom test average as a benchmark against which to evaluate changes in students' exam performance. In addition, given that all participants were instructed by the same teacher and were administered identical exams, the observed test score changes could not have been due to variability in teacher expertise or to differences in the complexity of individual tests. Finally, interviews at the end of the intervention with the teacher and students revealed that students did not receive any additional academic services during the intervention to support their learning in biology, minimizing the risk that supplementary instruction impacted changes in test grade.

2.4. General Procedures. All assessment and SREP training sessions were conducted by the self-regulated learning coach (SRC) prior to the school day in a large classroom at the target high school. The school administrators were not comfortable in allowing SREP to occur during the school day because of potential scheduling conflicts and missed classroom instruction. Trained graduate students administered the pretest and posttest measures and a cognitive screening tool (i.e., Wechsler Intelligence Scale for Children-Fourth Edition). The social validity questionnaires were administered at the conclusion of SREP, with student demographic data being provided by the school at the end of the academic year. All participants had the opportunity to attend 17 SREP sessions over the course of 12 weeks. A total of 24 sessions were initially planned (two sessions per week) but school functions, school closings (snow), and other logistical issues resulted in seven sessions being cancelled. Sessions were approximately 45 minutes in length, highly structured, and organized around the format and protocols of the SREP manual.

2.5. SREP Instructional Principles and Procedures. Given that extensive details about SREP are provided elsewhere [18, 28], we will only briefly describe the instructional format and sequence. In general, the primary purpose of SREP is to embed content-specific cognitive strategy instruction within a self-regulation process of thinking and action. In general, students are taught to think and act in a cyclical, regulated way while studying and preparing for biology exams. More specifically, students are taught to (a) set process goals (e.g., use of strategy) and outcome goals (e.g., specific test grade) and develop strategic plans prior to learning or studying, (b) implement, use, and monitor learning and regulatory strategies during studying activities, (c) and reflect 
on the quality and effectiveness of the learning strategies after test performance. This instructional focus directly corresponds to Zimmerman's [25] three-phase cyclical feedback loop.

Using a series of instructional modules, the SRC taught students how to (a) set goals and develop strategic plans, (b) use cognitive learning strategies (e.g., concepts maps) and regulatory strategies (e.g., self-monitoring, self-control) when studying at home, and (c) evaluate and reflect on their biology tests (see [18] for specific module details). The most comprehensive aspect of SREP training, however, involved strategy instruction. Throughout the intervention program students were taught both cognitive strategies, such as concept maps and mnemonic devices, and regulatory strategies, such as self-monitoring, help seeking, time management, and environmental structuring. The strategy instruction entailed using a well-defined instructional sequence: explanation of strategies, modeling, and guided practice [25]. The memory tactics and concept map modules were implemented during the fourth and fifth weeks of SREP, respectively. Each strategy module was administered over two sessions. The first session involved strategic instruction, with the second session devoted to teaching students how to monitor their rate of learning using the learning strategies (e.g., self-quizzes). From week six through the completion of the SREP, the SRC led students through successive cycles of guided practice in using cognitive strategies (e.g., concept maps) and various self-control strategies (e.g., environmental structuring, time management) in a self-regulated manner as determined by students' self-expressed needs. It is important to note that these latter sessions were highly collaborative and individualized in that students were encouraged to express their specific challenges when learning biology content or when using a cognitive strategy during studying at home.

An underlying theme in the SREP instruction is the alternation between the highly structured SREP sessions (which included high levels of feedback and guided practice opportunities when using cognitive strategies) and the independent use and monitoring of these strategies at home. The SRC not only provided students with ample practice opportunities during SREP to apply strategies to course content but also how to practice and track how well they learned using these strategies at home. As will be discussed across the case studies, students varied in how well they were able to independently use these strategies outside the presence of the SRC.

Finally, the SREP self-reflection module is one of the most important components of the program because it explicitly guides student reflection on whether they reached their goals, the potential reasons for their performance, and what they need to do strategically to improve. It is during this module when the SRC provides individualized and customized feedback to best address students' specific maladaptive beliefs and behaviors. Following the first two biology tests during SREP, the SRC administered the brief SRL microanalytic protocol to examine student attributions and adaptive inferences. Although the primary function of this qualitative data was to help the SRC guide intervention activities and reflective conversations, in this paper we present examples of students' microanalytic responses to illustrate the quality of their reflective thinking during the course of the intervention.

\section{Results and Case Study Analysis}

Multiple assessment tools and sources were used to examine the level of correspondence between biology test score patterns exhibited by each of the participants and their SREP attendance as well as shifts in their use of cognitive and regulatory strategies and motivation during and immediately following the intervention. For the metric SRL measures (i.e., SRSI-SR, SRSI-TRS, self-efficacy), we calculated reliability change index (RCI) scores to examine pretest-posttest changes in SRL and motivation beliefs. RCI procedures involved dividing pretest-posttest differences by the standard error of the differences between the two test scores [48, 49]. One can interpret an RCI of 1.96 as a statistically significant difference at a $P<0.05$ level, whereas an RCI of 2.33 or greater is significant at a $P<0.01$ level and is viewed as having greater clinical significance. Qualitative information gathered from field observations, microanalytic questions, and social validity questionnaires were used to supplement the quantitative measures.

3.1. SREP and Biology Exam Performance. Using descriptive analysis, it was observed that, in general, each of the participants showed positive gains when comparing their average pretest exam score to their average intervention score. However, there was a high level of variability in the pattern of specific intervention test scores across participants (see Table 2). For example, both Pauline and Vince showed steady improvement during the intervention, whereas Eric and John showed initial progress but then displayed a sharp decline in performance on the final test of the semester.

To interpret these case studies, we discussed normative changes in student biology test performance and then illustrated whether these test score patterns closely corresponded to shifts in their regulatory and motivated behaviors, their SREP attendance and punctuality, and their perceptions and motivation beliefs. A series of quantitative and qualitative assessment tools were used to accomplish this objective. To structure the narrative sequence for each case, we highlighted students' regulatory behaviors and motivation when beginning SREP, specific challenges that they exhibited or encountered, and the evolution of the quality of their regulatory perceptions, beliefs, and strategic behaviors during the intervention. Within this narrative, we address three overarching themes: (a) shifts in motivation beliefs and strategic or regulatory behaviors, (b) degree of convergence among assessment tools to support interpretive conclusions, and (c) correspondence between motivated and regulatory behaviors and intervention biology exam scores.

3.1.1. Vince and Pauline. On the first intervention exam, Vince and Pauline performed substantially below the class average. However, they both showed substantial growth during SREP. Vince performed 0.95 (raw score exam $=85 \%$ ) to 0.80 (raw score exam $=95 \%$ ) standard deviations above 
TABLE 2: Biology test performance of participants before and during SREP intervention.

\begin{tabular}{|c|c|c|c|c|c|c|}
\hline Participant name & $\begin{array}{c}\text { Baseline test } \\
\text { score average }^{\mathrm{a}} \\
M_{z \text {-score }}\left(M_{\text {raw score }}\right)\end{array}$ & $\begin{array}{c}\text { Intervention test } \\
\text { score average }{ }^{\mathrm{b}} \\
M_{z \text {-score }}\left(M_{\text {raw score }}\right)\end{array}$ & $\begin{array}{c}\text { Gain score } \\
M_{z \text {-score }}\left(M_{\text {raw score }}\right)\end{array}$ & $\begin{array}{l}\text { Intervention } \\
\text { test no. } 1 \\
z \text {-score (raw) }\end{array}$ & $\begin{array}{l}\text { Intervention } \\
\text { test no. } 2 \\
z \text {-score (raw) }\end{array}$ & $\begin{array}{c}\text { Intervention } \\
\text { test no. } 3 \\
z \text {-score (raw) }\end{array}$ \\
\hline Vince & $.26(76.3 \%)$ & $.42(85.3 \%)$ & $.16(9.0)$ & $-.50(76 \%)$ & $.95(85 \%)$ & $.80(95 \%)$ \\
\hline Pauline & $-.31(68.0 \%)$ & $-.05(79.7 \%)$ & $.26(11.7)$ & $-1.0(71 \%)$ & $.17(75 \%)$ & $.68(93 \%)$ \\
\hline Eric & $.14(74.8 \%)$ & $.43(84.0 \%)$ & $.29(9.2)$ & $.57(87 \%)$ & $.74(83 \%)$ & $-.02(82 \%)$ \\
\hline John & $-1.63(50.5 \%)$ & $-.84(67.3 \%)$ & $.79(16.8)$ & $-.60(75 \%)$ & $-.71(64 \%)$ & $-1.22(63 \%)$ \\
\hline Group Avg & $-.40(67.4 \%)$ & $-.02(79.1 \%)$ & $.38(11.7)$ & $-.40(77.3 \%)$ & $.29(76.8 \%)$ & $.06(83.3 \%)$ \\
\hline
\end{tabular}

$M_{z \text {-score }}$ : mean $z$-score. $M_{\text {raw score }}$ : mean raw exam score.

${ }^{a}$ means biology test scores prior to SREP. ${ }^{b}$ means biology test scores during SREP.

the class mean on the last two intervention exams, whereas Pauline performed 0.17 (raw score exam $=75 \%$ ) and 0.68 (raw score $_{\text {exam }}=93 \%$ ) standard deviations above the class average on the last two exams. Both Vince and Pauline clearly improved their test performance during the intervention in comparison to their pretest exam scores.

3.1.2. Vince: Link between Motivation, Regulation, and Achievement. Based on a review of records and several assessment tools used in this study, Vince presented as a highly interested and eager learner who underperformed academically relative to his effort and motives for achieving success. Vince's motivation to improve was demonstrated in his SREP attendance; Vince attended the highest percentage of SREP sessions of the four participants ( $82 \%$; see Table 3 ), arriving to most sessions on time and with classroom materials. In addition, at pretest, he exhibited relatively high perceptions of efficacy and reported that he frequently used different strategies when studying for biology tests (see Table 4).

Interestingly, Vince also displayed some awareness of specific areas of challenge for him. He self-reported that he struggled to consistently comprehend and understand biology course material, particularly technical vocabulary. During one of the initial sessions, the SRC noted that the technical vocabulary associated with biology represented a major hurdle for Vince and that he did not exhibit a strong repertoire of strategies for learning vocabulary. For example, Vince conveyed that his study plan consisted of looking over his notes and simply stating vocabulary words aloud to remember them (SREP field notes, March 5, 2008). At around the same time, Vince underperformed on a quiz of the skeletal system because he confused several anatomical terms (SREP field notes, March 17, 2008). He was disheartened by the results of this quiz because he had reportedly spent a considerable amount of time preparing. In short, despite exhibiting strong motivation and desire to perform well, Vince felt frustrated by his lack of success and struggles with learning key terms for tests. Vince's difficulty with vocabulary again surfaced during the SREP module devoted to teaching mnemonic strategies. During one particular session, Vince openly talked about his frustration when learning to pronounce complex or challenging technical vocabulary (SREP field notes, March 31, 2008).
It was not until the SRC began to explain and model specific tactics on how to learn key terms and to monitor how well he learned them when studying at home that Vince began to exhibit more strategic behaviors and improved test performance. Although he was initially resistant to using mnemonics to learn vocabulary words or to use self-quizzes to monitor his study approach, Vince gradually began to practice this tactic after receiving guided practice support and encouragement from the SRC (SREP field notes, April 2, 2008). Vince was similarly hesitant during the next session which focused on concept maps but, again, quickly embraced this strategy as the SRC systematically modeled and provided guided practice support (SREP field notes, April 4, 2008). His acceptance and application of these strategies were observed during a subsequent SREP session when both Vince and John began to refine their use of mnemonics, concept maps, and self-quizzing together (SREP field notes, April 16, 2008). Of particular interest is that Vince's desire to use concept maps is consistent with prior research showing that various types of graphic organizers often facilitate learning and comprehension with ELL students $[50,51]$. It is possible that Vince experienced greater success in learning when using these strategies and thus was highly motivated to use and apply them.

As predicted by the three-phase model of self-regulation [25], changes in Vince's use of concept maps and mnemonic devices coincided with adaptive changes in his self-reflective thoughts following exam performance, suggesting that Vince began to think about exam performance in relation to the strategies taught during SREP. For example, as part of the selfreflection module administered following his second biology test, Vince reported that learning key vocabulary terms was the primary barrier to his success. In addition, he attributed his performance on the second intervention exam, which was a large improvement from his first intervention exam, to the perceived "large amount of time he studied" and the use of "easier ways to remember more information about all of the subjects" (SRL microanalysis, May 5, 2008). These latter statements were in reference to the mnemonic devices and concept maps taught during SREP.

It was during this discussion that Vince spontaneously revealed to the SRC that he had received ELL services from the first to sixth grade, which he associated with his difficulty learning biology terms (SREP field notes, April 21, 2008). 
TABLE 3: Student attendance and tardiness during the SREP intervention.

\begin{tabular}{|c|c|c|c|c|c|c|c|c|}
\hline Participant & $\begin{array}{l}\text { Total SREP } \\
\text { attendance } \\
\text { ratio }^{\mathrm{a}}(\%)\end{array}$ & $\begin{array}{c}\text { Attendance } \\
\text { before test } \\
\text { no. } 1 \\
\text { ratio }^{\text {a }}(\%)\end{array}$ & $\begin{array}{c}\text { Attendance } \\
\text { before test } \\
\text { no. } 2 \\
\text { ratio }^{\text {a }}(\%)\end{array}$ & $\begin{array}{l}\text { Attendance } \\
\text { before test } \\
\text { no. } 3 \\
\text { ratio }^{\text {a }}(\%)\end{array}$ & $\begin{array}{c}\text { Total SREP } \\
\text { lateness } \\
\text { ratio }^{\mathrm{b}}(\%)\end{array}$ & $\begin{array}{c}\text { Lateness } \\
\text { before test } \\
\text { no. } 1 \\
\text { ratio }^{\mathrm{b}}(\%)\end{array}$ & $\begin{array}{c}\text { Lateness } \\
\text { before test } \\
\text { no. } 2 \\
\text { ratio }^{\mathrm{b}}(\%)\end{array}$ & $\begin{array}{c}\text { Lateness } \\
\text { before test } \\
\text { no. } 3 \\
\text { ratio }^{\text {b }}(\%)\end{array}$ \\
\hline Vince & $\begin{array}{c}14 / 17 \\
(82.4 \%)\end{array}$ & $3 / 3(100 \%)$ & $6 / 7(85.7 \%)$ & 5/7 (71.4\%) & $0 / 14(0 \%)$ & $0 / 3(0 \%)$ & $0 / 6(0 \%)$ & $0 / 5(0 \%)$ \\
\hline Pauline & $9 / 17$ (52.9\%) & $1 / 3(33 \%)$ & $3 / 7(42.8 \%)$ & $5 / 7(71.4 \%)^{c}$ & $1 / 9(11.1 \%)$ & $0 / 1(0 \%)$ & $0 / 3(0 \%)$ & $1 / 5(20 \%)$ \\
\hline Eric & $\begin{array}{c}13 / 17 \\
(76.5 \%)\end{array}$ & $2 / 3(75 \%)$ & $6 / 7(85.7 \%)$ & $5 / 7(71.4 \%)$ & $4 / 13(30.8 \%)$ & $0 / 2(0 \%)$ & $0 / 6(0 \%)$ & $4 / 5(80 \%)$ \\
\hline John & $\begin{array}{c}11 / 17 \\
(64.7 \%)\end{array}$ & $3 / 3(100 \%)$ & $5 / 7(71.4 \%)$ & $3 / 7(42.8 \%)$ & $6 / 11(54.5 \%)$ & $3 / 3(100 \%)$ & $1 / 5(20 \%)$ & $2 / 3(66.7 \%)$ \\
\hline
\end{tabular}

Attendance ratios and percentages reflect whether students showed up to a session regardless of lateness. Lateness was defined as being late to an SREP session by more than 15 minutes.

${ }^{a}$ Ratio pertains to the number of sessions students attended divided by the total number of sessions offered.

${ }^{b}$ Ratio pertains to the number of times students were late to an SREP session divided by the number of sessions attended.

${ }^{\mathrm{c}}$ Pauline missed the last session because she was on a family vacation.

TABLE 4: Reliability change index (RCI) scores across self-regulation and motivation measures.

\begin{tabular}{lcccccccccccc}
\hline \multirow{2}{*}{ Dependent measures } & \multicolumn{3}{c}{ Vince } & \multicolumn{3}{c}{ Pauline } & \multicolumn{3}{c}{ Eric } & \multicolumn{2}{c}{ John } \\
& Pretest & Posttest & RCI & Pretest & Posttest & RCI & Pretest & Posttest & RCI & Pretest & Posttest & RCI \\
\hline SRSI-MBE & 3.27 & 3.64 & 0.98 & 3.91 & 3.64 & -0.72 & 2.73 & 2.91 & 0.48 & 3.36 & 3.45 & 0.24 \\
SRSI-SLI & 3.25 & 3.63 & 0.99 & 3.25 & 3.38 & 0.34 & 2.63 & 3.13 & 1.30 & 3.38 & 3.50 & 0.31 \\
SRSI-MRB $^{\mathrm{a}}$ & 1.63 & 1.63 & 0.00 & 3.25 & 2.38 & $-2.00^{*}$ & 3.13 & 3.25 & 0.28 & 2.00 & 1.75 & -0.58 \\
SRSI-TRS $_{\text {SE outcomes }}^{2.38}$ & 2.69 & 0.84 & 1.69 & 3.08 & $3.75^{* *}$ & 1.85 & 3.00 & $3.10^{* *}$ & 2.23 & 2.69 & 1.24 \\
SE learning & 8.83 & 9.17 & 0.53 & 9.0 & 6.33 & $-4.16^{* *}$ & 10.0 & 6.83 & $-4.94^{* *}$ & 6.83 & 5.67 & -1.81 \\
\hline
\end{tabular}

MBE: managing behavior and environment. SLI: seeking and learning information. MRB: maladaptive regulatory behavior. TRS: teacher rating scale. SE: selfefficacy. RCI: reliability change index.

${ }^{a}$ Low scores represent fewer maladaptive regulatory behavior.

${ }^{*} P<.05$.

${ }^{* *} P<.01$

This reflection exercise marked an important shift for Vince because he began to attribute his exam outcomes to controllable factors (e.g., study strategies) that he could modify. Research has shown this type of attribution response to be quite adaptive in promoting more positive motivation and self-regulation $[52,53]$. In fact, during this particular selfreflection discussion, Vince spontaneously elected to expand his strategy plan for the third intervention exam to include asking his sister to quiz him on key terms and concepts (SREP field notes, April 21, 2008).

Not only did Vince become more strategic with how he learned information, but he also explored ways to structure his study sessions and to regulate his motivation and studying behaviors, such as time management, environmental structuring, and self-reinforcement (all components of the performance phase of the three-phase cyclical model). SRC field notes showed that Vince experimented with selfreinforcement, whereby he would award himself with an afterschool snack only after he completed his homework. Vince deemed this strategy effective because, as he revealed in an earlier SREP session, he would get distracted most often after he ate (SREP field notes, March 19, 2008). Over the course of the SREP intervention, Vince also recognized the value of time management as he reported using intermittent breaks of soccer to help him structure his studying and to enhance his time management (SREP field notes, May 19, 2008).

Although many of the behaviors and strategies that Vince exhibited were prompted and guided by the SRC, there was also evidence that Vince began to proactively and independently adapt and use strategies taught during SREP. For example, after learning how to use concept maps and summarization techniques during an SREP session, Vince independently and spontaneously (i.e., without prompting from the SRC or teacher) developed a series of potential test questions to guide his studying at home the following weekend (SREP field notes, April 16, 2008). Vince brought these questions into the following SREP session to share with John and to receive feedback regarding their appropriateness and quality. Vince exhibited similar behaviors prior to the third intervention exam, as he generated additional questions to quiz himself as he studied for this final unit exam (SREP field notes, May 19, 2008). In short, by the end of SREP, Vince exhibited a profile of high achievement and adaptive motivated and self-regulatory behaviors. In fact, after SREP had ended, Vince met with the SRC to debrief about the program. 
During this conversation he spontaneously revealed that prior to SREP he would typically gloss over difficult words because focusing on them elicited feelings of embarrassment and frustration. However, he reported that during SREP he recognized the value of using SREP strategies to deal with the problem as well as the use of alternative strategies to find definitions of unfamiliar words, such as using the Internet (SREP field notes, May 28, 2008). Theorists have described these types of proactive or self-generated behaviors as being reflective of adaptive levels of personal agency and regulatory sophistication $[25,54]$.

Another important theme involved the level of convergence between pretest-posttest changes in quantitative measures of SRL (i.e., self-report questionnaires and teacher rating scales), the field note observations, and data derived from microanalytic reflection questions. For Vince, there was poor convergence between most quantitative measures and the qualitative assessment tools. For example, RCI analysis of both the self-report and teacher version of the SRSI showed that there was no improvement in Vince's strategic approach to learning biology course content (see Table 4). That is, despite evidence for shifts in his strategic behaviors as noted previously, Vince did not perceive that he used strategies more frequently nor did his teacher report that he was more strategic during classroom activities. This lack of convergence may suggest that students may have difficulty accurately reporting their strategic behaviors, a premise consistent with prior research $[55,56]$ or that self-report questionnaires may often lack the sensitivity needed to capture specific shifts in students' use of cognitive or regulatory strategies.

In terms of Vince's profile of self-efficacy perceptions, he displayed relatively high efficacy perceptions at the beginning of SREP. These high levels of efficacy were consistent with his high level of motivated behaviors exhibited at the outset of the program and his strong SREP attendance. Unlike his SREP peer participants, however, Vince sustained these high beliefs throughout the program, with his change in efficacy for regulated learning narrowly missing statistical significance (see Table 4). By sustaining his belief in personal capability and through recognizing that learning study strategies were connected with his improved test grades, Vince displayed the most consistent pattern of SREP attendance and was rarely late to the intervention sessions.

3.1.3. Pauline: Link between Motivation, Regulation, and Achievement. As indicated in record reviews, Pauline displayed adequate achievement and intellectual skills, but struggled on tasks that involved self-directed or independent activities. She was a good candidate for SREP in this context because test preparation was the key task of interest that necessitated a high level of self-initiation and self-direction to perform well. Based on SREP field notes, Pauline was distracted, frustrated, and disorganized during the initial SREP sessions and often exhibited poor strategic behaviors and motivation beliefs. For example, when asked to describe her approach to studying at the beginning of SREP, Pauline related that she saved all her studying for the weekend (SREP field notes, March 5, 2008) and that her typical approach to learning and recalling key terms and course content was to "keep going over them until my brain hurts" (SREP field notes, March 17, 2008). Pauline expressed frustration during initial SREP sessions because she did not perform well on exams despite her efforts and often forgot to turn her assignments in on time, even when she had completed the assignments (SREP field notes, March 17, 2008). Pauline's difficulties with learning course material and time management appeared to impact her mood and thoughts, as the SRC noted that she was often tired, distracted, and confused during initial sessions. On one occasion, Pauline expressed a declining level of self-efficacy, stating "everything is difficult for me" (SREP field notes, March 31, 2008). Given this pattern of beliefs and behaviors, it made sense that Pauline attended only four out of the first 10 sessions and that her perceived efficacy to regulate her learning was only at a moderate level (see Tables 3 and 4).

Despite exhibiting maladaptive behaviors at the outset of SREP, Pauline evinced an important shift in regulatory thinking and behaviors immediately before the second exam. She also appeared to become more entrenched in strategic thinking during the self-reflection module administered following the second intervention test. When probed with an attribution question during the self-reflection module ("What is the main reason why you got this test grade?"), Pauline identified running out of time when taking the test and spending too much time studying a narrow set of topics as the key causes of her performance (SREP microanalysis, April 28, 2008). Thinking about her test outcomes in terms of specific strategies was highly adaptive because she recognized that, with the help of the SRC who had modeled such thinking during SREP sessions, she could improve her test performance if she modified her study plan (a type of controllable, internal, and unstable attribution). As part of the self-reflection session, Pauline also made effective adaptive inferences by identifying controllable actions she could take to improve her next exam grade. For example, she cited studying "equally on each section" as one method for ensuring that she did not neglect key test topics (SREP microanalysis, April 28, 2008). In addition, the specificity of her plan increased as she reported practical methods to better manage her time and quality of learning. For example, she determined a specific amount of time that she would devote to studying each night (rather than wait for the weekend) and planned to utilize specific tactics, such as, "thinking about questions and easier strategies" to help her remember key terms and content. Recognizing that anxiety was a selfreported area of concern, Pauline included the use self-talk in her strategic plan for the third test by reminding herself "the more I study the better my grade will be" (SRL microanalysis, May 6, 2008).

Of particular importance from a self-regulatory perspective was that Pauline increased how frequently she sought out support prior to the third intervention biology test, such as asking her older siblings for assistance (SREP field notes, April 21, 2008). This behavior was highly adaptive because it enabled her to clarify points of confusion and to receive support and confirmation regarding the appropriateness of her approach to her studies. Furthermore, help seeking is 
widely regarded as an essential regulatory skill that is used by highly effective learners [57, 58]. During subsequent sessions, Pauline also reported that she proactively researched mnemonic devices on the Internet to help her remember content prior to an exam on the circulatory system. It is important to note that these latter behaviors occurred immediately following an SREP session on help-seeking and information-seeking strategies. In other words, these anecdotal observations suggest that Pauline attempted to apply and adapt strategies that she learned during SREP to enhance her independent studying at home.

Another important shift for Pauline occurred following her second exam, when she recognized that attending SREP sessions on a more regular basis would help her improve her test performance by getting more practice and feedback from the SRC. In fact, Pauline attended five of the last seven SREP sessions that occurred prior to the third intervention exam, with one of those absences resulting from a family vacation rather than her decision to not attend. Consistent with her increased level of self-directedness and initiative, Pauline spoke with the SRC about how to prepare early for the third intervention exam given that she was going to miss the SREP session prior to her exam (SREP field notes, April 28, 2008). Despite beginning SREP with poor levels of organization and self-directed behaviors, Pauline gradually initiated her own attempts to learn and sought out the appropriate assistance when struggling.

Furthermore, Pauline's self-reported perceptions of strategy use, teacher ratings, and SRC observations during SREP showed a moderate amount of convergence. In general, Pauline perceived that she engaged in less maladaptive regulatory behaviors (e.g., lack of organization, forgetfulness) at the end of the intervention, $(\mathrm{RCI}=2.00, P<0.01)$. These self-reported behaviors were consistent with field note observations about Pauline's behaviors highlighted previously as well as teacher ratings showing a significant increase (pretest to posttest) in Pauline's regulatory and motivated behaviors during biology class, $(\mathrm{RCI}=3.75, P<0.01)$. Interestingly, no significant pretests to posttest change was found regarding Pauline's perceptions of how frequently she used adaptive cognitive and regulatory strategies during learning. This lack of correspondence between her perceptions of strategy use and the changes in strategies observed by the SRC and biology teacher is consistent with findings related to Vince. That is, significant changes on the SRSI adaptive subscales may not have been observed because either Pauline did not accurately report these behaviors due to overestimation at pretest or due to poor awareness of what she actually did to prepare for exams.

Analysis of Pauline's declining self-efficacy throughout the intervention further underscores the latter point about inaccuracies in student self-perceptions. Pauline began SREP with very high levels of self-efficacy to perform well in biology but displayed relatively lower levels of efficacy to manage and regulate her learning. Her low efficacy for regulation made sense given that organization and regulation were specific areas that Pauline and her teachers noted as personal areas of weakness. Her inflated efficacy for biology outcomes, however, suggested a lack of awareness on her part regarding being able to learn biology material well, particularly because her pretest biology test average was so low. In analyzing pretest-posttest differences across these two self-efficacy measures, her self-efficacy for attaining biology outcomes showed a significant decline whereas her efficacy for regulation did not change. The decline in her efficacy for biology outcomes can be understood from a calibration perspective. That is, as Pauline became more aware of her learning challenges or weakness, even with improved biology test scores, her perceived capabilities shifted. This is an important phenomenon because given the high level of monitoring and self-awareness enhancement that occurs during SREP, students will not only become more aware of progress that they make but also their personal limitations and specific areas of struggle.

3.1.4. Eric and John. Although Eric and John exhibited different pretest exam score averages, with Eric's pretest average slightly above the classroom mean $\left(z=0.14, M_{\text {exam }}=74.8\right)$ and John's profile substantially below the mean $(z=-1.63$, $\left.M_{\text {exam }}=50.5\right)$, they demonstrated a similar pattern of exam performance over the course of the intervention (see Table 2). That is, both students showed an initial increase in their biology exam scores relative to their pretest averages but struggled to sustain this performance over time.

\subsubsection{Eric: Link between Motivation, Regulation, and Achieve-} ment. Eric exhibited strong performance on his first two biology intervention tests but exhibited slightly below average performance on his third exam. Interestingly, the majority of the data gathered from quantitative and qualitative methods supported the premise that Eric's behaviors during class time and during SREP sessions were adaptive, at least initially, but that he was unable to sustain these behaviors throughout the intervention and struggled to implement what he learned during SREP without external support.

Throughout SREP, Eric attended most of the sessions and was very engaged during the initial part of the training program. During the initial SREP sessions, students identified the reasons why they displayed inconsistent performance in biology. Eric expressed several controllable or modifiable factors, including difficulty with recalling information following studying, poor knowledge of test preparation strategies, and difficulty concentrating or avoiding distraction when doing work at home (SREP field notes, March 5, 2008). Prior to the first intervention exam, Eric expressed a strong desire to refine and extend his repertoire of strategies in preparation for upcoming exams, including rewriting notes and looking over labs as opposed to simply reading over notes (SREP field notes, March 12, 2008). His level of strategic engagement was also apparent in preparation for the second biology exam as he reported using self-quizzing tactics as a way to monitor his learning. He also demonstrated a strong interest and skill in being able to generate his own mnemonic strategies to address his self-reported problems with recall for exams (SREP field notes, April 2, 2008). His extremely positive attendance and punctuality to SREP, along with his interest in applying learning strategies to improve learning, was highly 
consistent with his strong performance on the first two biology exams (see Table 2).

Interestingly, following the second intervention exam, field note observations and self-reflection discussions revealed that Eric began to disengage from SREP. As part of the self-reflection module following this exam, Eric reported that he "did not study very specific material," and that this was the key factor affecting his grade (SREP microanalysis, April 28, 2008). In terms of what he believed he needed to do to improve (adaptive inference), Eric indicated that he needed to become "more detailed in studying and reviewing" (SREP microanalysis, April 28, 2008). However, during this self-reflection discussion, Eric conveyed that he would like to continue to improve his test grades, but he was unwilling to put forth the necessary effort to do so (SREP field notes, April 28, 2008). It was following this exam when Eric began to show signs of disengagement, characterized by excessive lateness to SREP sessions (see Table 3).

Many theorists argue that the motivation to engage in learning is largely determined by one's motivation beliefs, such as self-efficacy, task interest and value, and conceptions of ability $[25,59,60]$. In Eric's case, his declining motivation could be explained by several of these beliefs, including his tendency to perceive exam performance as a stable trait (i.e., conceptions of ability; [59]), his declining self-efficacy, and his devaluing of biology class (task value; [25]). Eric exhibited a large and statistically significant decrease in his efficacy beliefs for attaining positive biology outcomes $(\mathrm{RCI}=-4.94$, $P<0.01)$ from pretest to posttest. Similar to Pauline, at pretest Eric's self-efficacy for biology outcomes was at the upper extreme (i.e., a raw score of 10) and plausibly overinflated relative to his average level of biology performance at pretest. Given that SREP sessions often included conversations centering on students' specific strategic weaknesses along with potential suggestions for improvement, it is highly probable that he became more aware of his personal weaknesses as well as the inherent obstacles to learning success. As a result, his perceptions about his ability to perform well were also adversely impacted. According to Bandura [61], students who begin to doubt their capabilities are much more likely to avoid work and to display poor effort. It is also noteworthy that towards the end of SREP, Eric began to exhibit behaviors suggesting that he did not place biology class as a priority in his life. For example, during one session prior to the third intervention exam, Eric doubted whether he would study for the third intervention exam as planned because he wanted to visit his brother, who was in college, since it was more enjoyable (SREP field notes, May 8, 2008).

Although it is difficult to ascertain whether Eric's value perceptions were directly influenced by his lowered selfefficacy (i.e., "if I cannot do something well, I do not value it"), there was also qualitative data suggesting that he possessed an entity conception of ability rather than a more incremental one [59]. Entity theorists tend to view ability as a fixed capacity whereas incremental theorists perceive it to be malleable with practice and effort. Entity theorists would perceive low levels of effort as reflecting high capability. During an SREP session, Eric talked about his older brother performing exceedingly well in high school and in college while also conveying his perception that his brother did not appear to try very hard to attain these grades (SREP field notes, April 28, 2008). Although Eric expected that he would experience similar success, it appeared that he displayed poor awareness about the level of effort that his brother probably put forth to maintain this high level of performance or the level of effort that he personally needed to sustain a high level of performance. As a result, Eric believed that he could experience the same success as his brother without much effort. However, when he realized during SREP that he might need to exert high levels of effort to learn challenging concepts or to be a consistent performer, he appeared to display avoidance and resistance for the remainder of SREP.

An alternative explanation as to why Eric may have disengaged and experienced lower self-efficacy was that he was unsure how to enact more strategic forms of studying without external support. This is an intriguing possibility because Eric's dwindling attendance and engagement in SREP may have limited the extent to which he effectively applied the study strategies taught during previous SREP sessions. That is, Eric received specific, performance-related feedback from the SRC on how to implement study strategies in a selfregulated manner. By modeling how learning strategies could be used in a self-regulated manner, the SRC demonstrated what could be done to better learn biology content. In the context of the SREP session, Eric felt confident about what strategies he could use and how these strategies could be adapted. However, in the absence of the feedback rich setting of SREP, Eric was unable to independently use the strategies he learned. Although speculative, it is possible that upon becoming aware of his struggle to do so at home, his interest and self-efficacy for learning declined. Whereas Vince and Pauline expressed excitement and enthusiasm at the prospect of independently altering their use of strategies to increase their grades, it appeared that Eric did not experience those positive feelings. It is possible that Eric did not know how to apply these strategies at home without the support of the SRC and was not willing to exert the effort needed to do so.

In terms of his self-perception of strategy use, RCI procedures revealed no significant changes from pretest to posttest (see Table 4), suggesting that his profile of regulatory skills did not improve during the intervention. The lack of positive change in strategy self-report questionnaires mirrored the declines in his SRL behaviors and motivation that were observed in his poor attendance record and his lowered levels of self-efficacy. Interestingly, the biology teacher reported that Eric had generally become more engaged and motivated during his participation in SREP, rating him in a significantly more positive way at posttest than pretest $(\mathrm{RCI}=3.10$, $P<0.01)$. This level of divergence was interesting because it suggested that while Eric's regulatory and motivated behaviors improved in biology class (i.e., a context whereby he could receive external support) his interest and motivation to perform independent studying activities at home declined. From an instructional perspective, it was clear that Eric needed additional supports to help modify his maladaptive thinking and to sustain his strategic efforts when studying at home. 
3.1.6. John: Motivation Beliefs and Regulatory Behaviors. Despite possessing adequate academic and intellectual skills, a record review and teacher reports showed that John struggled with motivation, organization, and self-regulation at the beginning of SREP. For the first two sessions, John arrived approximately forty minutes late, effectively missing the entirety of the content presented (SREP attendance notes). Pulled aside by the SRC to inquire about his tardiness issues, John stated that he arrived late because he missed the bus (SREP field notes, March 12, 2008). The SRC discussed the importance of arriving on time and worked with John to identify how he could arrive on time. John attended the next SREP session on time, but struggled with attendance and punctuality for the remainder of the intervention (SREP attendance notes). In addition to routinely arriving late, John attended most SREP sessions without his materials and made comments regarding projects for other classes that he had not finished on time (SREP field notes, March 17, 2008). These behaviors were highly consistent with teacher reports of his poor organization skills. Given his extremely sporadic and infrequent attendance to SREP sessions and the high level of consistency in his weak self-regulatory processes and strategic behaviors, we will discuss a few key issues pertaining to John's deficient motivation and regulatory skills rather than providing a sequential account of his behaviors during SREP as was illustrated with the other cases.

First, John reported relatively low perceptions of efficacy at pretest, suggesting that prior to SREP, he did not possess a high level of confidence about regulating his learning in biology or performing well in the course (see Table 4). Although John improved his exam performance by about 0.79 standard deviations, his biology exam performance was still near failing and far below his classmates. Given his normatively weak performances in biology, it makes sense that he did not "see" his test score improvement; thus, he sustained low self-efficacy for biology outcomes and even exhibited significant declines in his self-efficacy for regulated learning $(\mathrm{RCI}=-2.58, P<0.01)$. As stated earlier, research has shown that when students display poor levels of selfefficacy they become disengaged from learning [61].

There was also evidence that John possessed poor metacognitive skills regarding his knowledge and awareness of the nature and format of his biology exams. In discussions that occurred during the self-reflection module following intervention exam two, it was revealed that John erroneously interpreted attaining a 93 on a 150 -point test as equivalent to the same score on a 100-point test (SREP field notes, April 28, 2008). Similarly, John believed preparing for a 150point test did not require more effort than preparing for a 100-point test (SREP field notes, April 28, 2008). It was not until the SRC discussed these misinterpretations that John acknowledged the discrepancy between his perceptions and the demands of studying for biology tests of varying complexity and length. Self-regulation researchers have consistently found that students who demonstrate poor awareness of task demands or their own skill levels are typically those who underperform in school [62-64]. Although enhancing John's self-awareness and poor motivation (i.e., SREP attendance) became the primary instructional goal of the SRC, poor attendance and punctuality limited the opportunities for the SRC to impact John's strategic skills, motivational beliefs (self-efficacy, perceived instrumentality), and cognitive and metacognitive approach to studying for biology exams.

Finally, for John, there was complete convergence amongst SRL assessment tools and his performance on biology exams. In short, all measures demonstrated that John did not exhibit changes in his regulatory behaviors or strategies during the intervention nor did he substantially improve his exam grades. For example, based on both selfreport (SRSI-SR) and teacher rating scales (SRSI-TRS), there were no significant changes in his perceptions of strategy use and regulatory behaviors from pretest to posttest (see Table 4). Similarly, John exhibited maladaptive behaviors that limited the extent to which he benefited from the SREP intervention, including poor time management and selfreflection, sporadic attendance, and poor punctuality to SREP sessions (see Table 3). John attended only $65 \%$ of the sessions $(11 / 17)$ and was late more than 15 minutes for six of those sessions. Thus, he not only missed approximately half of the sessions, but also key instructional content on those days in which he did attend. In sum, John's consistent below average test performance clearly converged with his lack of growth in strategic and metacognitive skills, his poor motivation, and his low attendance of SREP sessions.

\section{Conclusions and Areas of Future Research}

This study examined the relationship between shifts in student SRL and motivation during an intervention and their test performance changes in a specific academic content area. In general, students who attended SREP sessions on a regular basis and practiced using the strategies taught during SREP exhibited substantial improvement. This paper also descriptively illustrated the association between students' motivation beliefs and self-reflection processes (e.g., attributions) with their enactment of regulatory and learning strategies; a finding that parallels the SRL literature $[6,38,65,66]$. Of particular importance was the varied responsiveness of students to the SRL intervention, ranging from "steady improvement" (Vince and Pauline), to "progress with difficulty sustaining motivation" (Eric), to "slow or minimal progress" (John). The utility of a multidimensional SRL assessment approach for assessing the dynamic, context-specific nature of SRL was also underscored. That is, self-report questionnaires, teacher ratings, SRL microanalytic questions, and field observations can provide a robust foundation for interpreting and explaining student behaviors during an intervention.

4.1. Relation between SREP and Science Achievement. All four students who received SREP showed improved biology test scores relative to their individual pretest score averages. Based on findings from this study as well as those from Cleary et al. [18], SREP participants have demonstrated $z$-score changes ranging from 0.13 to $1.5(M=0.55$; Median $=0.36)$, with most showing significant changes in their motivated and self-regulated behaviors (see Tables 2 and 5). In addition, social validity information gathered from parents, teachers, 
TABLE 5: Biology test performance gain scores observed in Cleary et al. [18].

\begin{tabular}{|c|c|c|c|}
\hline $\begin{array}{l}\text { Participant } \\
\text { name }\end{array}$ & $\begin{array}{c}\text { Baseline test score } \\
\text { average } \mathrm{a}^{\mathrm{a}} \\
M_{z \text {-score }} \\
\left(M_{\text {raw score }}\right) \\
\end{array}$ & $\begin{array}{c}\text { Intervention test } \\
\text { score average }^{\mathrm{b}} \\
M_{z \text {-score }} \\
\left(M_{\text {raw score }}\right) \\
\end{array}$ & $\begin{array}{c}\text { Gain score } \\
M_{z \text {-score }} \\
\left(M_{\text {raw score }}\right)\end{array}$ \\
\hline Jamal & $-.77(67.2 \%)$ & $.18(83.0 \%)$ & $.95(15.8)$ \\
\hline Jordan & $-.47(70.8 \%)$ & $.09(81.7 \%)$ & $.56(10.9)$ \\
\hline Nancy & $-.84(66.2 \%)$ & $.66(90.7 \%)$ & $1.50(24.5)$ \\
\hline Ronaldo & $-.15(75.2 \%)$ & $.09(81.7 \%)$ & $.24(6.5)$ \\
\hline Tony & $-.23(74.2 \%)$ & $.01(79.7 \%)$ & $.24(5.5)$ \\
\hline
\end{tabular}

Mean biology test scores prior to SREP. ${ }^{\mathrm{b}}$ Mean biology test score during SREP.

and students in the current study and prior research [18] indicated that SREP was deemed to be a highly acceptable, relevant, and important intervention that has great potential as an academic intervention in high school contexts.

The primary purpose of the present study, however, was devoted to examining how shifts in student SRL processes, motivation beliefs, and motivation-related behaviors corresponded to the instructional opportunities provided in SREP and to changes in students' in biology test grades. Our results showed that changes in these SRL processes were clearly linked to shifts in exam performance and SREP attendance. This relationship was strengthened through our use of a multidimensional assessment approach as well as the control of several extraneous variables. For example, using $z$-score transformations and selecting students from a biology course taught by the same teacher controlled for the impact of teacher skill, instructional approach, and exam difficulty. That is, if the teacher developed easier exams or enhanced the quality of her teaching during the same semester in which SREP was implemented, all students would have likely benefitted and thus one would probably not have observed normative changes in participant test scores. The fact that a couple of the students performed substantially above the class average also makes it less likely that regression to the mean accounted for improving test scores. Furthermore, each participant's pretest biology exam score was calculated from several exam grades obtained over an extended time period (5 months); the use of a relatively stable baseline over a long time period minimized the potential that typical development or maturation contributed to the observed effects. Finally, interviews with students towards the end of the SREP intervention revealed that they had not received any tutoring or supplemental instruction in biology besides SREP during the course of the intervention.

The analysis of individual cases suggested that SREP afforded or created structured opportunities for students to optimize their motivation and to enhance their SRL skills. That is, the SRC modeled and provided guided practice in using specific learning strategies, encouraged students to monitor their use and application of these strategies during test preparation outside of school, and engaged students in discourse about the link between the use of learning and regulatory strategies during most SREP sessions. Those students who consistently attended SREP sessions, such as Vince and Pauline, had greater opportunities to learn, refine, and adapt their use of strategies and to develop more positive motivation beliefs that enhanced their future learning efforts. In contrast, John exhibited extreme lateness and poor attendance to SREP sessions and did not provide any evidence of improved regulation or motivation during the intervention.

The primary implication from this analysis connects shifts in student SRL and motivation processes during the intervention (i.e., either increased or decreased) with changes in biology test grades. For both Pauline and Vince, practicing and applying specific cognitive and self-regulatory strategies while studying at home appeared to lead to substantial improvements in test performance. However, this improvement occurred in tandem with increased self-reflection on how their biology test scores related to the strategies they used to prepare for tests. Furthermore, Eric and John missed extensive instructional time during the last seven or eight SREP sessions, which collectively were devoted to guiding students to independently use the skills taught while studying at home. These sessions were devoted to shaping students' thought processes and behaviors by providing repeated guided practice opportunities for adapting and refining self-motivation beliefs and the use of cognitive and regulatory strategies. Eric and John would have clearly benefitted from these types of discussions as they showed either poor motivation or skill in independently using these strategies when studying at home.

At a more general level, it is important to realize that some students who exhibit the types of negative belief patterns illustrated by Eric and John will naturally display resistance to change and may actually disengage from learning. Consistent with response-to-intervention (RTI) models $[67,68]$, interventionists must recognize individual differences in how students respond to SRL interventions. Given that not all students respond similarly necessitates the use of a flexible service-delivery model that adapts sessions to most effectively address individual concerns and issues.

4.2. Patterns of SRL during SREP: Implications and Future Research. Self-regulation has been conceptualized as a multidimensional process that integrates forethought, performance, and self-reflection processes [23, 25]. Given the breadth and depth of the SRL construct, researchers have argued that multiple assessment tools should rely on a variety of sources to measure changes in students' regulatory beliefs and behaviors [35]. In this study, we illustrated that various assessment tools can be used to establish convergence regarding changes in self-regulatory processes and behaviors. However, there was a large disconnect between information generated from student self-report questionnaires and the data obtained through teacher and SRC observations and the contextualized student verbalizations during SREP. In general, no pretest-posttest differences were observed across any of the three subscales of the SRSI-SR for the four participants, except for the significant improvement displayed by Pauline on the SRSI-SR Maladaptive Regulation subscale. Collectively, these results suggest that student perceptions regarding the frequency with which they used cognitive and 
TABLE 6: Student, parent, and teacher responses to social validity questionnaire.

\begin{tabular}{|c|c|c|c|c|c|}
\hline \multicolumn{2}{|l|}{ Student version } & \multicolumn{2}{|l|}{ Teacher version } & \multicolumn{2}{|l|}{ Parent version } \\
\hline Acceptability & $M(\mathrm{SD})$ & Acceptability & $M(\mathrm{SD})^{\mathrm{a}}$ & Acceptability & $M(\mathrm{SD})$ \\
\hline $\begin{array}{l}\text { The strategies that the tutors } \\
\text { taught me were very important }\end{array}$ & $4.0(.82)$ & $\begin{array}{l}\text { The strategies that the tutors used in } \\
\text { the program are very important for } \\
\text { student success }\end{array}$ & $4.0(-)$ & $\begin{array}{l}\text { The strategies that the tutors taught } \\
\text { my child are very important for } \\
\text { his/her success }\end{array}$ & $4.0(0.0)$ \\
\hline $\begin{array}{l}\text { I would recommend this program } \\
\text { to a friend who was struggling in } \\
\text { school. }\end{array}$ & $4.0(.82)$ & $\begin{array}{l}\text { I would recommend this program } \\
\text { to parents of other children who are } \\
\text { struggling in school }\end{array}$ & $5.0(-)$ & $\begin{array}{l}\text { I would recommend this program } \\
\text { to parents of other children who are } \\
\text { struggling in school }\end{array}$ & $4.3(.58)$ \\
\hline $\begin{array}{l}\text { The tutoring forced me to do a lot } \\
\text { of extra unnecessary work }\end{array}$ & $3.3(1.7)$ & $\begin{array}{l}\text { The tutoring involved too much } \\
\text { work for the students }\end{array}$ & $4.0(-)$ & $\begin{array}{l}\text { The tutoring involved too much } \\
\text { work for my child }\end{array}$ & $4.3(.58)$ \\
\hline $\begin{array}{l}\text { Going to the tutoring was a waste } \\
\text { of my time }{ }^{b}\end{array}$ & $4.3(.96)$ & $\begin{array}{l}\text { I am happy that the students } \\
\text { participated in the program }\end{array}$ & $4.0(-)$ & $\begin{array}{l}\text { I am happy that my } \\
\text { participated in the }\end{array}$ & $4.7(.58)$ \\
\hline Importance of outcomes & $M(\mathrm{SD})$ & Importance of outcomes & $M(\mathrm{SD})$ & Importance of outcomes & $M(\mathrm{SD})$ \\
\hline $\begin{array}{l}\text { The tutoring helped me to become } \\
\text { more aware of the reasons why I } \\
\text { sometimes struggle in school }\end{array}$ & $4.0(0.0)$ & $\begin{array}{l}\text { The tutoring helped the students } \\
\text { recognize the reasons why they } \\
\text { were having difficulty in school }\end{array}$ & $4.0(-)$ & $\begin{array}{l}\text { The tutoring helped my child } \\
\text { recognize the reasons why he/she } \\
\text { was having difficulty in school }\end{array}$ & $4.0(0.0)$ \\
\hline $\begin{array}{l}\text { I think about myself in a more } \\
\text { positive way because of the } \\
\text { tutoring sessions }\end{array}$ & $4.0(0.0)$ & $\begin{array}{l}\text { The students think about } \\
\text { themselves in a more positive way } \\
\text { because of the tutoring }\end{array}$ & $4.0(-)$ & $\begin{array}{l}\text { My child thinks about him/herself } \\
\text { in a more positive way because of } \\
\text { the tutoring }\end{array}$ & $4.0(0.0)$ \\
\hline $\begin{array}{l}\text { I am more confident in my ability } \\
\text { to manage things in school because } \\
\text { of the tutoring }\end{array}$ & & $\begin{array}{l}\text { The students seem to be more } \\
\text { confident in school because of the } \\
\text { tutoring }\end{array}$ & $4.0(-)$ & $\begin{array}{l}\text { My child seem to be more confident } \\
\text { in school because of the tutoring }\end{array}$ & $4.3(.58)$ \\
\hline $\begin{array}{l}\text { The tutoring helped me realize that } \\
\text { I can change or improve my } \\
\text { learning in school }\end{array}$ & $4.0(0.0)$ & $\begin{array}{l}\text { The tutoring helped the students } \\
\text { realize that they can change or } \\
\text { improve their learning in school }\end{array}$ & $4.0(-)$ & $\begin{array}{l}\text { The tutoring helped my child realize } \\
\text { that he/she can change or improve } \\
\text { his/her learning in school }\end{array}$ & $4.3(.58)$ \\
\hline $\begin{array}{l}\text { The tutor taught me strategies that } \\
\text { will help me to manage things in } \\
\text { school better }\end{array}$ & $4.3(.50)$ & $\begin{array}{l}\text { The tutoring helped the students } \\
\text { manage the demands of school } \\
\text { more effectively }\end{array}$ & $4.0(-)$ & $\begin{array}{l}\text { The tutoring helped my child } \\
\text { manage the demands of school } \\
\text { more effectively }\end{array}$ & $3.7(.58)$ \\
\hline Total average & 4.0 & Total average & 4.1 & Total average & 4.2 \\
\hline
\end{tabular}

Student version $(N=4)$. Teacher version $(N=1)$. Parent version $(N=3)$. All measures were based on a five-point Likert scale ranging from 1 (strongly disagree) to 5 (strongly agree).

${ }^{a}$ Standard deviation (SD) was not applicable because only one teacher completed the questionnaire.

${ }^{\mathrm{b}}$ Items were reverse scored to reflect adaptive perceptions of satisfaction.

regulatory strategies did not change. However, information gathered from the SRSI teacher rating scale as well as from field note observations of students' verbalizations, regulatory behaviors, and work products, suggested that changes did occur, at least on some level, for all participants (John being the lone exception).

Although caution should be applied in drawing overly broad conclusions regarding the appropriateness or adequacy of self-report questionnaires, an interesting point is that if self-report questionnaires, which are typically the most common form of SRL assessment, was the only type of SRL measure used in this study our conclusions would have varied greatly from those generated by using our multidimensionalassessment methodology [35]. Along a similar vein, a limitation of this study was the use of only a single type of self-report motivational belief measure (i.e., self-efficacy measure). It would have been helpful to include multiple measures of motivation beliefs, such as task values and goal orientation, so that a more robust foundation could have been used to interpret shifts in students' effort and persistence.

In terms of the appropriateness of using self-report questionnaires, the present study corroborated previous research demonstrating that self-report surveys diverge from other measures of SRL; a finding that is consistent with the SRL assessment literature showing that what students say that they do (self-report questionnaires) is often not what they actually do $[55,56]$. This measurement characteristic can be problematic or advantageous to researchers or interventionists, depending on their research goals and objectives. If a researcher is primarily interested in examining the efficacy of an intervention, self-report questionnaires can be particularly problematic because students tend to overestimate their skills, behaviors, and beliefs at pretest, thereby potentially obscuring any "true" gains that might occur. It is highly probable that this occurred for many of the students in our study.

Conversely, if the goal of an SRL assessment tool is to guide or inform instruction, then self-report measures are critical because they can potentially help to identify inaccurate student judgments and perceptions. The importance of student miscalibration was highlighted extensively in the present study. All participants, aside from John, provided extremely high pretest self-efficacy perceptions for attaining positive outcomes in biology class even though their biology 
pretest exam performance was not strong. Although overestimates of personal capability can be advantageous in sustaining effort and motivation [62], they can be problematic when they signify poor metacognition and awareness about their personal strengths and weaknesses. However, from the perspective of an interventionist or a practitioner, poor calibration or self-assessment skills can be used as a guide for instruction or intervention. Several researchers have discussed how interventions can be employed to enhance the accuracy with which students self-assess their performance capabilities and to help them become more aware of task demands and their own knowledge and skills [7, 69-71].

In terms of future research, alternative research methodologies, such as quasi-experimental or experimental designs, should attempt to more closely examine and strengthen the premise that SREP causes changes in science achievement and self-regulation. Issues pertaining to external validity and inter-rater agreement for behavioral observations are also important in examining SREP. Although the present sample was diverse in terms of gender and ethnicity, it is important to consider the effectiveness of SREP with students exhibiting disabilities, such as a learning disability and Attention Deficit Hyperactivity Disorder (given their welldocumented struggles with strategy use and regulation), and across different areas within and outside of science education. It is also important for future researchers to carefully consider performance outcomes that occur on a more frequent basis. In the current study, students took class exams approximately once every three weeks. Hence, the number of opportunities for them to engage in the cyclical, regulatory process was restricted. From our vantage point, more frequent performance outcomes would allow students greater opportunities to evaluate and to recognize the strong link that exists between their strategic behaviors and academic outcomes. In addition, future research should explore transfer effects associated with providing multiple opportunities for students to learn and practice using strategies.

It is also important to consider the instructional context in which SREP tutoring sessions took place and how this context may have greatly impacted the frequency with which academically at-risk students attended the program. Due to school administrator stipulations, SREP was presented as a "before school program." Since it occurred outside of the typical school day, presenting this program to students created a challenge for engaging and enlisting students who displayed resistance (e.g., John) to coming to the program. From our perspective, it is critical to implement programs, such as SREP, during the regular school day and to perhaps offer this program as part of a package of remedial academic programs or Tier III intervention programs used in responseto-intervention service-delivery frameworks.

Finally, it is important for researchers to strongly consider how student developmental factors and the nature of contextual demands influence academic outcomes when implementing and evaluating SREP. For example, young children and those in the primary school years (e.g., Kindergarten to 5 th grade) show the capacity to learn and adapt SRL skills [72]. However, it remains unclear at this point how SREP could be adapted and refined to best meet the needs of younger children. In addition, the nature of academic tasks and the demands for independence and self-sufficiency in the primary grades are much less intensive than those observed during the high school years. Researchers interested in employing SREP with younger children would benefit from considering how to infuse SRL principles within classrooms to optimize SRL and motivation and/or to include small group SREP sessions within the climate and culture of a typical classroom.

\section{Appendix}

For more details see Table 6.

\section{Acknowledgments}

This study was funded in part by a grant from the Society for the Study of School Psychology. The authors also express their sincerest thanks to Anastasia Kitsantas and Audrey Lubin for their helpful comments on earlier drafts of this paper. Both authors were affiliated with UWM when the study was conducted.

\section{References}

[1] M. Boekaerts, P. R. Pintrich, and M. Zeidner, Handbook of SelfRegulation, Academic Press, San Diego, Calif, USA, 2000.

[2] J. G. Borkowski, R. S. Weyhing, and M. Carr, "Effects of attributional retraining on strategy-based reading comprehension in learning-disabled students," Journal of Educational Psychology, vol. 80, no. 1, pp. 46-53, 1988.

[3] L. S. Fuchs, D. Fuchs, K. Prentice et al., "Enhancing third-grade students' mathematical problem solving with self-regulated learning strategies," Journal of Educational Psychology, vol. 95, no. 2, pp. 306-315, 2003.

[4] D. L. Butler, "The strategic content learning approach to promoting self-regulated learning: a report of three studies," Journal of Educational Psychology, vol. 90, no. 4, pp. 682-697, 1998.

[5] S. Graham and K. R. Harris, "Almost 30 years of writing research: making sense of it all with The Wrath of Khan," Learning Disabilities Research \& Practice, vol. 24, no. 2, pp. 58-68, 2009.

[6] D. H. Schunk and B. J. Zimmerman, Motivation and SelfRegulated Learning: Theory, Research, and Applications, Lawrence Erlbaum Associates, Mahwah, NJ, USA, 2008.

[7] T. J. Cleary, "School-based motivation and self-regulation assessments: an examination of school psychologist beliefs and practices," Journal of Applied School Psychology, vol. 25, no. 1, pp. 71-94, 2009.

[8] T. J. Cleary, A. Gubi, and M. V. Prescott, "Motivation and self-regulation assessments: professional practices and needs of school psychologists," Psychology in the Schools, vol. 47, no. 10, pp. 985-1002, 2010.

[9] M. L. Wehmeyer, M. Agran, and C. Hughes, "A national survey of teachers' promotion of self-determination and studentdirected learning," Journal of Special Education, vol. 34, no. 2, pp. 58-68, 2000. 
[10] E. A. Davis, "Prompting middle school science students for productive reflection: generic and directed prompts," Journal of the Learning Sciences, vol. 12, no. 1, pp. 91-142, 2003.

[11] R. Millar and J. F. Osborne, Beyond 2000: Science Education for the Future, King's College, London, UK, 1998.

[12] E. E. Peters and A. Kitsantas, "Self-regulation of student epistemic thinking in science: the role of metacognitive prompts," Educational Psychology, vol. 30, no. 1, pp. 27-52, 2010.

[13] G. Schraw, K. J. Crippen, and K. Hartley, "Promoting selfregulation in science education: metacognition as part of a broader perspective on learning," Research in Science Education, vol. 36, no. 1-2, pp. 111-139, 2006.

[14] G. M. Sinatra and G. Taasoobshirazi, "Intentional conceptual change: the self-regulation of science," in Handbook of SelfRegulation of Learning and Performance, B. J. Zimmerman and D. H. Schunk, Eds., pp. 203-216, Routledge, New York, NY, USA, 2011.

[15] National Governors Association Center for Best Practices and Council of Chief State School Officers, Common core state standards for English language arts and literacy history/social studies, science and technical subjects, 2010, http://www .corestandards.org/assets/CCSSI_ELA\%20Standards.pdf.

[16] U.S. Department of Education, National Center for Educational Statistics, The condition of education 2007, DOE Publication No. 2007-064, 2007, http://nces.ed.gov/pubs2007/2007064.pdf.

[17] A. S. Labuhn, S. Bögeholz, and M. Hasselhorn, "Promoting learning through a classroom-based intervention in science education," Zeitschrift für Pädagogische Psychologie, vol. 22, pp. 13-24, 2008.

[18] T. J. Cleary, P. Platten, and A. Nelson, "Effectiveness of the self-regulation empowerment program (SREP) with urban high school youth: an initial investigation," Journal of Advanced Academics, vol. 20, pp. 70-107, 2008.

[19] C. E. Weinstein and T. Acee, "Helping college students become more strategic and self-regulated learners," in Applications of Self-Regulated Learning Across Diverse Disciplines: A Tribute to Barry J. Zimmerman, H. Bembenutty, T. J. Cleary, and A. Kitsantas, Eds., 2012.

[20] M. Gettinger and J. K. Seibert, "Contributions of study skills to academic competence," School Psychology Review, vol. 31, no. 3, pp. 350-365, 2002.

[21] D. Ramdass and B. J. Zimmerman, "Effects of self-correction strategy training on middle school students' self-efficacy, selfevaluation, and mathematics division learning," Journal of Advanced Academics, vol. 20, pp. 18-41, 2008.

[22] N. Rathvon, Effective School Interventions, The Guilford Press, New York, NY, USA, 2nd edition, 2008.

[23] P. R. Pintrich, "The role of goal orientation in self-regulated learning," in Handbook of Self-Regulation, M. Boekaerts, P. R. Pintrich, and M. Zeidner, Eds., pp. 451-502, Academic Press, San Diego, Calif, USA, 2000.

[24] D.H. Schunk and, "Social cognitive theory and self-regulated learning," in Self-Regulated Learning and Academic Achievement, B. J. Zimmerman and D. H. Schunk, Eds., pp. 125-151, Lawrence Erlbaum Associates, Mahwah, NJ, USA, 2nd edition, 2001.

[25] B. J. Zimmerman, "Attaining self-regulation: a social cognitive perspective," in Handbook of Self-Regulation, M. Boekaerts, P. R. Pintrich, and M. Zeidner, Eds., pp. 13-39, Academic Press, San Diego, Calif, USA, 2000.
[26] A. Bandura, Social Foundations of Thoughts and Action: A Social Cognitive Theory, Prentice Hall, Englewood Cliffs, NJ, USA, 1986.

[27] N. M. Clark, "The use of self-regulation intervention in managing chronic disease," in Applications of Self-Regulated Learning Across Diverse Disciplines: A Tribute to Barry J. Zimmerman, $\mathrm{H}$. Bembenutty, T. J. Cleary, and A. Kitsantas, Eds., 2012.

[28] T. J. Cleary and B. J. Zimmerman, "Self-Regulation Empowerment Program: a school-based program to enhance selfregulated and self-motivated cycles of student learning," Psychology in the Schools, vol. 41, no. 5, pp. 537-550, 2004.

[29] M. Bong, "Within-grade changes in Korean girls' motivation and perceptions of the learning environment across domains and achievement levels," Journal of Educational Psychology, vol. 97, no. 4, pp. 656-672, 2005.

[30] A. F. Hadwin, P. H. Winne, D. B. Stockley, J. C. Nesbit, and C. Woszczyna, "Context moderates students' self-reports about how they study," Journal of Educational Psychology, vol. 93, no. 3, pp. 477-487, 2001.

[31] T. Urdan and C. Midgley, "Changes in the perceived classroom goal structure and pattern of adaptive learning during early adolescence," Contemporary Educational Psychology, vol. 28, no. 4, pp. 524-551, 2003.

[32] D. L. Butler, B. Beckingham, and H. J. N. Lauscher, "Promoting strategic learning by eighth-grade students struggling in mathematics: a report of three case studies," Learning Disabilities Research \& Practice, vol. 20, no. 3, pp. 156-174, 2005.

[33] J. T. Guthrie, A. Wigfield, and K. C. Perencevich, "Scaffolding for motivation and engagement in reading," in Motivating Reading Comprehension: Concept-Oriented Reading Instruction, J. T. Guthrie, A. Wigfield, and K. C. Perencevich, Eds., pp. 55-86, Lawrence Erlbaum Associates, Mahwah, NJ, USA, 2004.

[34] D. H. Schunk and C. W. Swartz, "Goals and progress feedback: effects on self-efficacy and writing achievement," Contemporary Educational Psychology, vol. 18, no. 3, pp. 337-354, 1993.

[35] D. Butler, "Investigating self-regulated learning using in-depth case studies," in Handbook of Self-Regulation of Learning and Performance, B. J. Zimmerman and D. H. Schunk, Eds., pp. 346-360, Routledge, New York, NY, USA, 2011.

[36] J. W. Creswell, Qualitative Inquiry and Research Design: Choosing among Five Approaches, Sage, Thousand Oaks, Calif, USA, 2nd edition, 2007.

[37] R. K. Yin, Case Study Research Design and Methods, Sage, Thousand Oaks, Calif, USA, 4th edition, 2009.

[38] T. J. Cleary, "The development and validation of the selfregulation strategy inventory-self-report," Journal of School Psychology, vol. 44, no. 4, pp. 307-322, 2006.

[39] T. J. Cleary and P. P. Chen, "Self-regulation, motivation, and math achievement in middle school: variations across grade level and math context," Journal of School Psychology, vol. 47, no. 5, pp. 291-314, 2009.

[40] G. Callan and T. J. Cleary, "A teacher rating scale to examine student self-regulation in math contexts," in Proceedings of the Annual Meeting of American Education Research Association, Vancouver, Canada, 2012.

[41] A. Bandura, "Guide for creating self-efficacy scales," in SelfEfficacy Beliefs of Adolescents, F. Pajares and T. Urdan, Eds., pp. 307-338, Information Age, Greenwich, Conn, USA, 2006.

[42] Y. J. Joo, M. Bong, and H. J. Choi, "Self-efficacy for self-regulated learning, academic self-efficacy, and internet self-efficacy in web-based instruction," Educational Technology Research and Development, vol. 48, no. 2, pp. 5-17, 2000. 
[43] F. M. Gresham, D. L. MacMillan, M. E. Beebe-Frankenberger, and K. M. Bocian, "Treatment integrity in learning disabilities intervention research: do we really know how treatments are implemented?" Learning Disabilities Research and Practice, vol. 15, pp. 198-205, 2000.

[44] M. M. Wolf, "Social validity: the case for subjective measurement or how applied behavior analysis is finding its heart," Journal of Applied Behavior Analysis, vol. 11, no. 2, pp. 203-214, 1978.

[45] T. J. Cleary, "Emergence of self-regulated learning microanalysis: historical overview, essential features, and implications for research and practice," in Handbook of Self-Regulation of Learning and Performance, B. J. Zimmerman and D. H. Schunk, Eds., pp. 329-345, Routledge, New York, NY, USA, 2011.

[46] T. J. Cleary, B. J. Zimmerman, and T. Keating, "Training physical education students to self-regulate during basketball free throw practice," Research Quarterly for Exercise and Sport, vol. 77, no. 2, pp. 251-262, 2006.

[47] M. K. DiBenedetto and B. J. Zimmerman, "Differences in selfregulatory processes among students studying science: a microanalytic investigation," International Journal of Educational \& Psychological Assessment, vol. 5, no. 1, pp. 2-24, 2010.

[48] L. Christensen and J. L. Mendoza, "A method of assessing change in a single subject: an alteration of the RC index," Behavior Therapy, vol. 17, no. 3, pp. 305-308, 1986.

[49] N. S. Jacobson and P. Truax, "Clinical significance: a statistical approach to defining meaningful change in psychotherapy research," Journal of Consulting and Clinical Psychology, vol. 59, no. 1, pp. 12-19, 1991.

[50] J. K. Klingner, A. G. Boardman, A. M. Eppolito, and E. A. Schonewise, "Supporting adolescent English Language Learners' reading in the content areas," Learning Disabilities, vol. 10, pp. 35-64, 2012.

[51] J. E. Hart, "Strategies for culturally and linguistically diverse youth with specal needs," Preventing School Failure, vol. 53, pp. 197-208, 2009.

[52] M. M. Clifford, "The effects of ability, strategy, and effort attributions for educational, business, and athletic failure," British Journal of Educational Psychology, vol. 56, no. 2, pp. 169-179, 1986.

[53] N. C. Hall, R. P. Perry, J. G. Chipperfield, R. A. Clifton, and T. L. Haynes, "Enhancing primary and secondary control in achievement settings through writing-based attributional retraining," Journal of Social and Clinical Psychology, vol. 25, no. 4, pp. 361-391, 2006.

[54] A. Bandura, "Social cognitive theory: an agentic perspective," Annual Review of Psychology, vol. 52, pp. 1-26, 2001.

[55] M. V. J. Veenman, F. J. Prins, and J. Verheij, "Learning styles: self-reports versus thinking-aloud measures," British Journal of Educational Psychology, vol. 73, no. 3, pp. 357-372, 2003.

[56] P. H. Winne and D. Jamieson-Noel, "Exploring students' calibration of self reports about study tactics and achievement," Contemporary Educational Psychology, vol. 27, no. 4, pp. 551-572, 2002.

[57] S. A. Karabenick and J. L. Berger, "Help seeking as a selfregulated learning strategy," in Applications of Self-Regulated Learning across Diverse Disciplines: A Tribute to Barry J. Zimmerman, H. Bembenutty, T. J. Cleary, and A. Kitsantas, Eds., 2012.

[58] S. A. Karabenick and R. S. Newman, Eds., Help Seeking in Academic Settings: Goals, Groups, and Contexts, Lawrence Erlbaum Associates, Mahwah, NJ, USA, 2006.
[59] C. S. Dweck and A. Master, "Self-theories motivate selfregulated learning," in Motivation and Self-Regulated Learning: Theory, Research, and Applications, D. H. Schunk and B. J. Zimmerman, Eds., pp. 31-51, Lawrence Erlbaum Associates, Mahwah, NJ, USA, 2008.

[60] J. S. Eccles and A. Wigfield, "Motivational beliefs, values, and goals," Annual Review of Psychology, vol. 53, pp. 109-132, 2002.

[61] A. Bandura, Self-Efficacy: The Exercise of Control, W.H. Freeman, New York, NY, USA, 1997.

[62] L. Bol, R. Riggs, D. J. Hacker, D. Dickerson, and J. Nunnery, "The calibration accuracy of middle school students in math classes," Journal of Research in Education, vol. 21, pp. 81-96, 2010.

[63] P. P. Chen, "Exploring the accuracy and predictability of the self-efficacy beliefs of seventh-grade mathematics students," Learning and Individual Differences, vol. 14, no. 1, pp. 79-92, 2002.

[64] R. M. Klassen, "Too much confidence? The self-efficacy of adolescents with learning disabilities," in Self-Efficacy Beliefs of Adolescents, F. Pajares and T. Urdan, Eds., pp. 181-200, Information Age, Greenwich, Conn, USA, 2006.

[65] C. A. Wolters, "Regulation of motivation: evaluating an underemphasized aspect of self-regulated learning," Educational Psychologist, vol. 38, no. 4, pp. 189-205, 2003.

[66] B. J. Zimmerman, A. Bandura, and M. Martinez-Pons, "Self-motivation for academic attainment: the role of selfefficacy beliefs and personal goal-setting," American Educational Research Journal, vol. 29, pp. 663-676, 1992.

[67] D. Marston, “Tiers of intervention in responsiveness to intervention: prevention outcomes and learning disabilities identification patterns," Journal of Learning Disabilities, vol. 38, no. 6, pp. 539-544, 2005.

[68] W. D. Tilly, "The evolution of school psychology to sciencebased practice: problem-solving and the three-tiered model," in Best Practices in School Psychology-5, A. Thomas and J. Grimes, Eds., pp. 17-36, National Association of School Psychologists, Bethesda, Md, USA, 2008.

[69] P. P. Chen and P. D. Rossi, "Utilizing calibration accuracy information with adolescents to improve academic learning and performance," in Applications of Self-Regulated Learning across Diverse Disciplines: A Tribute to Barry J. Zimmerman, $\mathrm{H}$. Bembenutty, T. J. Cleary, and A. Kitsantas, Eds., 2012.

[70] L. T. Flannelly, K. J. Flannelly, and B. A. Cox, "Evaluating improvements in nursing staff at a state psychiatric hospital," Issues in Mental Health Nursing, vol. 22, no. 6, pp. 621-632, 2001.

[71] J. L. Nietfeld, L. Cao, and J. W. Osborne, "The effect of distributed monitoring exercises and feedback on performance, monitoring accuracy, and self-efficacy," Metacognition and Learning, vol. 1, no. 2, pp. 159-179, 2006.

[72] N. E. Perry, "Young children's self-regulated learning and contexts that support it," Journal of Educational Psychology, vol. 90, no. 4, pp. 715-729, 1998. 

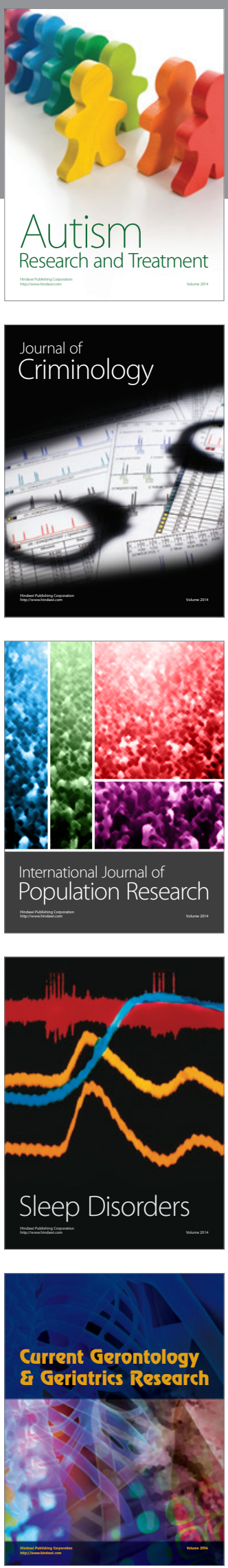
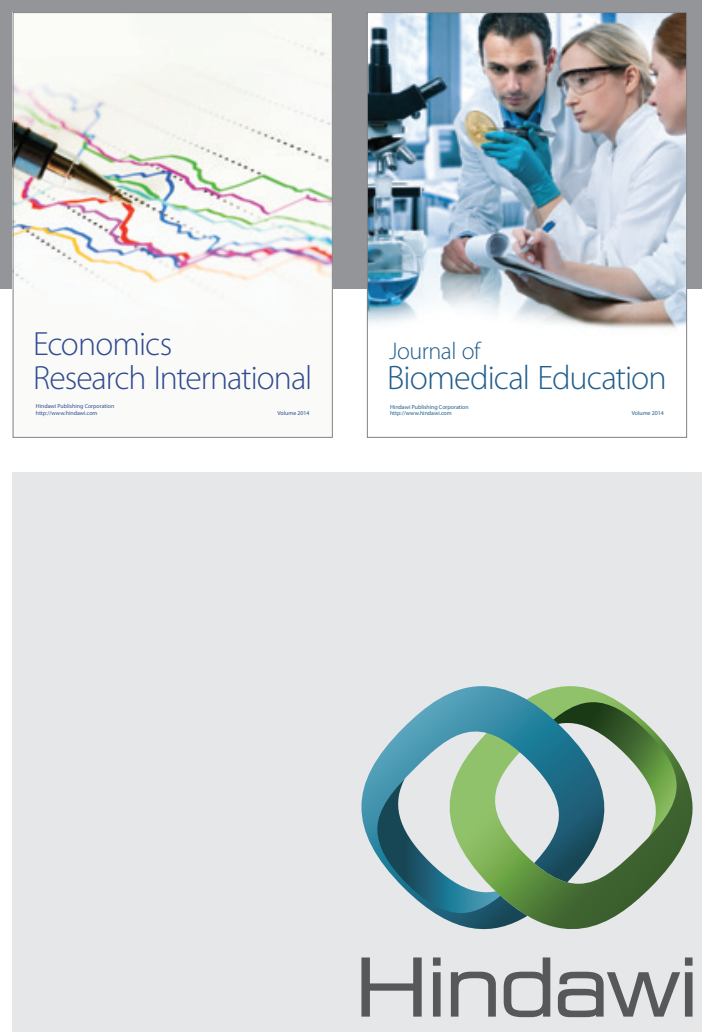

Submit your manuscripts at

http://www.hindawi.com
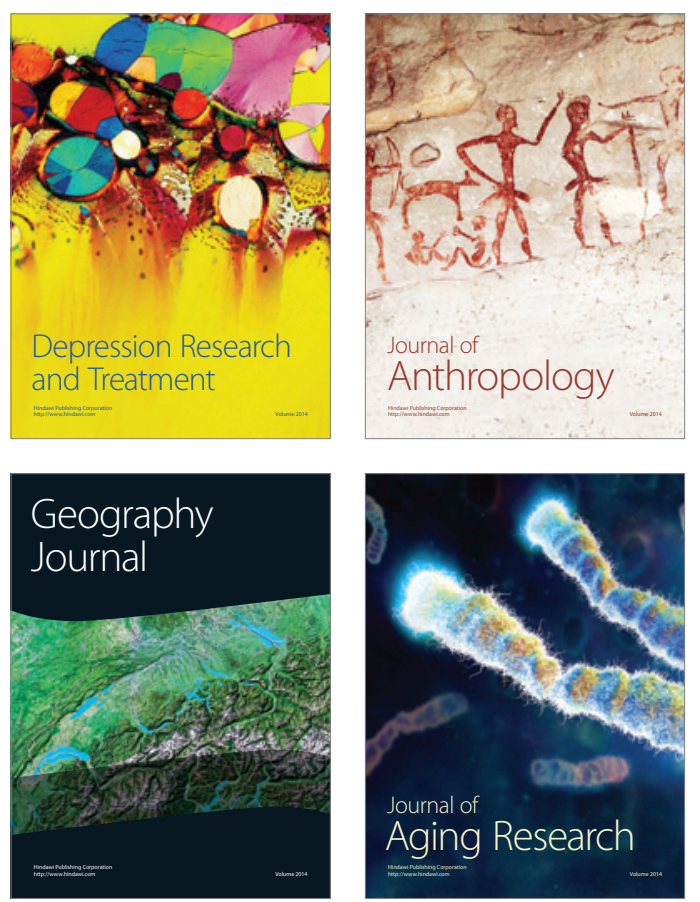
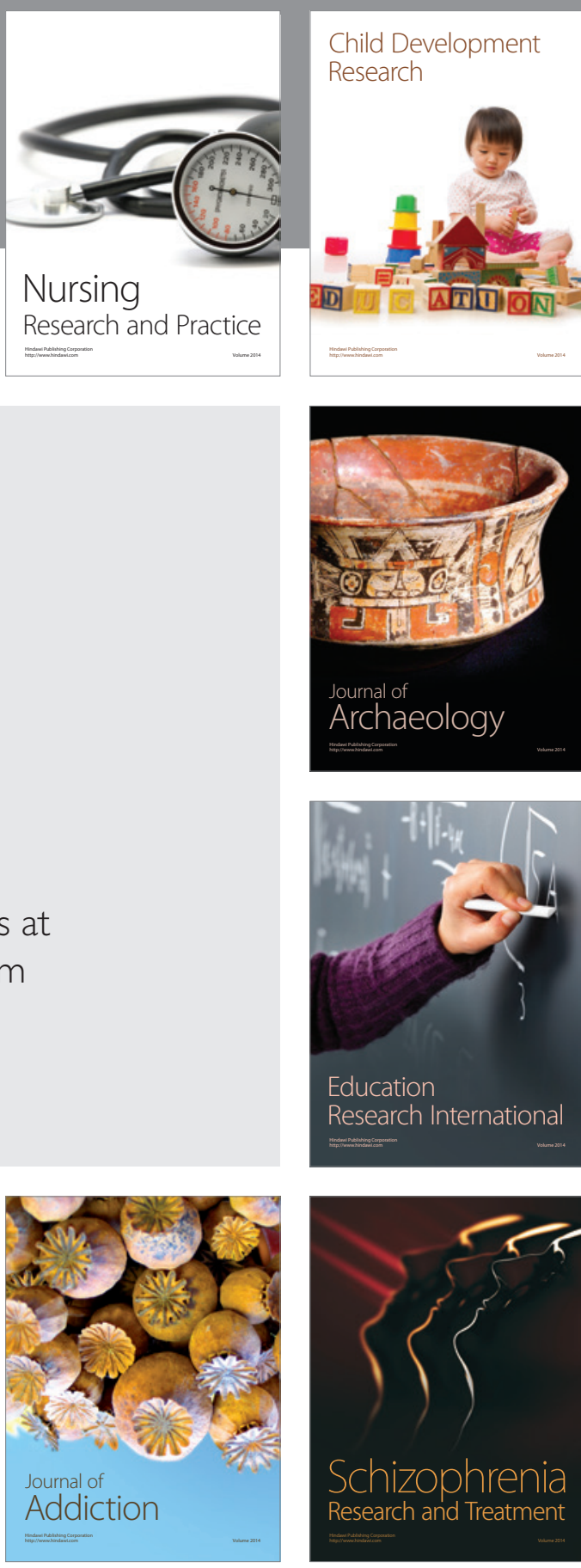

(D)
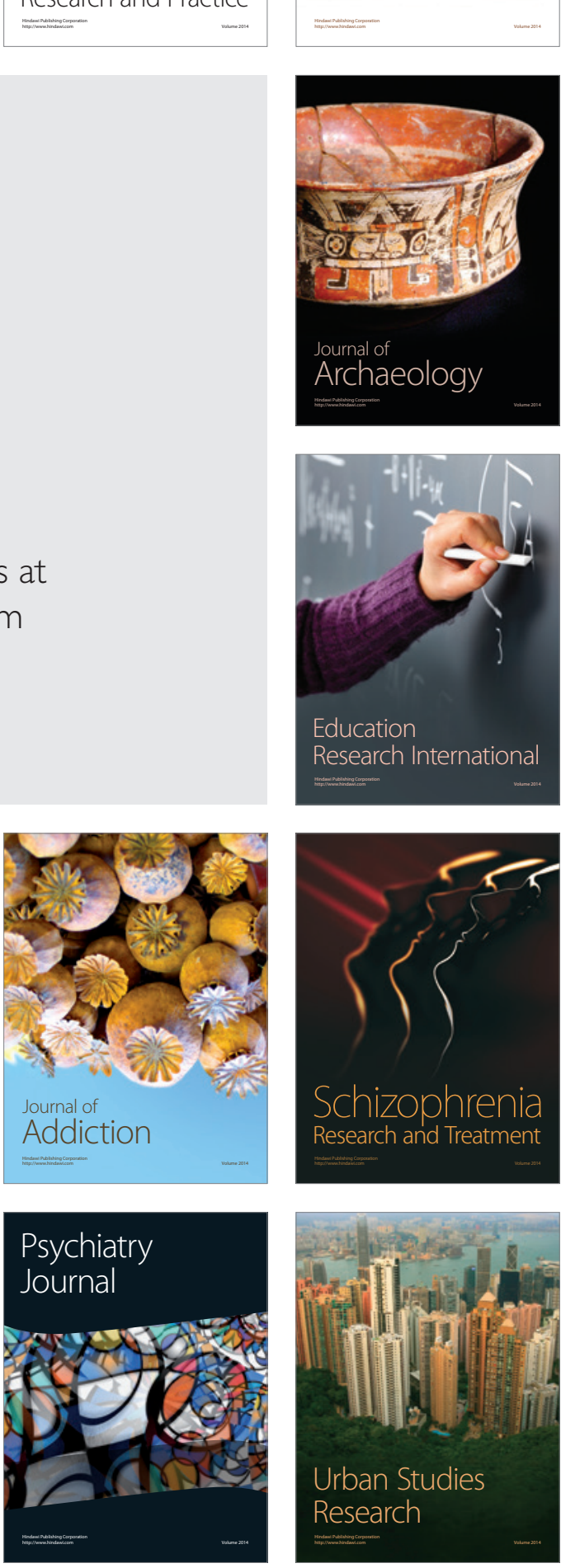